\title{
ADVANCED HYBRID PARTICULATE COLLECTOR - PILOT-SCALE TESTING
}

Final Topical Report

(for the reporting period January 29 through September 30, 2001)

Prepared for:

AAD Document Control

U.S. Department of Energy

National Energy Technology Laboratory

PO Box 10940, MS 921-143

Pittsburgh, PA 15236-0940

Cooperative Agreement No. DE-FC26-98FT40321; UND Fund 4713

Performance Monitor: William Aljoe

Prepared by:

Ye Zhuang Stanley J. Miller Michael E. Collings Michelle R. Olderbak

Energy \& Environmental Research Center University of North Dakota

PO Box 9018 Grand Forks, ND 58202-9018 


\section{DOE DISCLAIMER}

This report was prepared as an account of work sponsored by an agency of the United States Government. Neither the United States Government, nor any agency thereof, nor any of their employees makes any warranty, express or implied, or assumes any legal liability or responsibility for the accuracy, completeness, or usefulness of any information, apparatus, product, or process disclosed or represents that its use would not infringe privately owned rights. Reference herein to any specific commercial product, process, or service by trade name, trademark, manufacturer, or otherwise does not necessarily constitute or imply its endorsement, recommendation, or favoring by the United States Government or any agency thereof. The views and opinions of authors expressed herein do not necessarily state or reflect those of the United States Government or any agency thereof.

This report is available to the public from the National Technical Information Service, U.S. Department of Commerce, 5285 Port Royal Road, Springfield, VA 22161; phone orders accepted at (703) 487-4650.

\section{ACKNOWLEDGMENT}

This report was prepared with the support of the U.S. Department of Energy (DOE) National Energy Technology Laboratory Contract No. DE-FC26-98FT40321. However, any opinions, findings, conclusions, or recommendations expressed herein are those of the authors(s) and do not necessarily reflect the views of DOE.

\section{EERC DISCLAIMER}

LEGAL NOTICE This research report was prepared by the Energy \& Environmental Research Center (EERC), an agency of the University of North Dakota, as an account of work sponsored by National Energy Technology Laboratory. Because of the research nature of the work performed, neither the EERC nor any of its employees make any warranty, express or implied, or assume any legal liability or responsibility for the accuracy, completeness, or usefulness of any information, apparatus, product, or process disclosed, or represents that its use would not infringe privately owned rights. Reference herein to any specific commercial product, process, or service by trade name, trademark, manufacturer, or otherwise does not necessarily constitute or imply its endorsement or recommendation by the EERC. 


\section{TABLE OF CONTENTS}

LIST OF FIGURES $\ldots \ldots \ldots \ldots \ldots \ldots \ldots \ldots \ldots \ldots \ldots \ldots \ldots \ldots \ldots \ldots$

LIST OF TABLES $\ldots \ldots \ldots \ldots \ldots \ldots \ldots \ldots \ldots \ldots \ldots \ldots \ldots \ldots \ldots \ldots \ldots \ldots \ldots \ldots \ldots$

EXECUTIVE SUMMARY $\ldots \ldots \ldots \ldots \ldots \ldots \ldots \ldots \ldots \ldots \ldots \ldots \ldots \ldots \ldots \ldots$ iv

INTRODUCTION $\ldots \ldots \ldots \ldots \ldots \ldots \ldots \ldots \ldots \ldots \ldots \ldots \ldots \ldots \ldots \ldots \ldots$

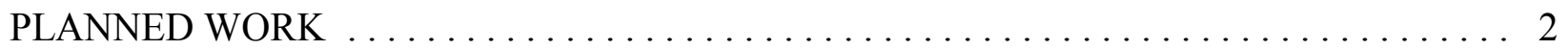

AHPC PILOT TESTING RESULTS $\ldots \ldots \ldots \ldots \ldots \ldots \ldots \ldots \ldots \ldots \ldots \ldots \ldots$

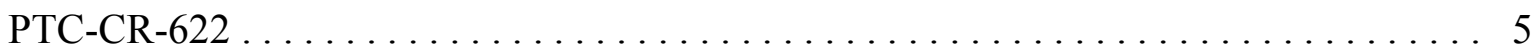

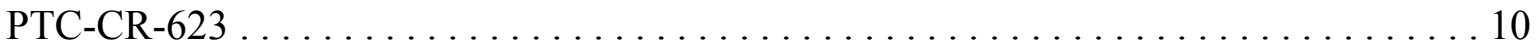

EVALUATION OF ESP PERFORMANCE IN THE AHPC UNIT UNDER THE

PERFORATED PLATE CONFIGURATION $\ldots \ldots \ldots \ldots \ldots \ldots \ldots \ldots \ldots \ldots \ldots$

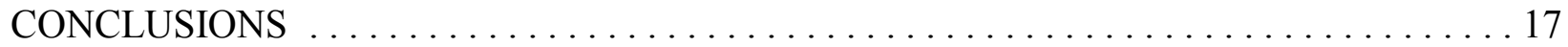

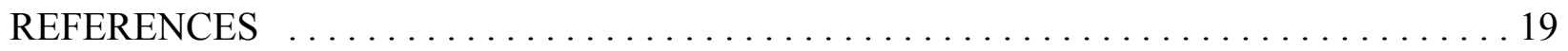




\section{LIST OF FIGURES}

1 AHPC pilot-scale configuration at the EERC $\ldots \ldots \ldots \ldots \ldots \ldots \ldots \ldots \ldots$

2 Bag-cleaning interval for PTC-CR-622-1 $\ldots \ldots \ldots \ldots \ldots \ldots \ldots \ldots \ldots \ldots \ldots \ldots \ldots$

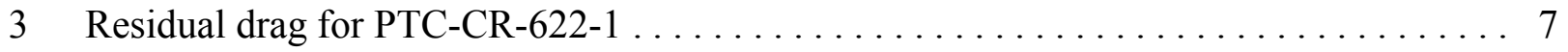

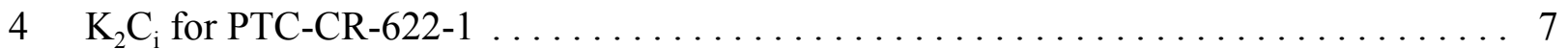

5 Fly-ash deposited pattern on the perforated plates at the pilot-scale AHPC $\ldots \ldots \ldots .8$

6 Bag-cleaning intervals for PTC-CR-622-2 and PTC-CR-622-3 $\ldots \ldots \ldots \ldots \ldots \ldots$

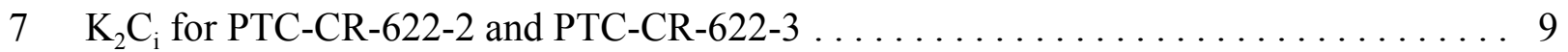

8 Residual drag for PTC-CR-622-2 and PTC-CR-622-3 $\ldots \ldots \ldots \ldots \ldots \ldots \ldots \ldots$

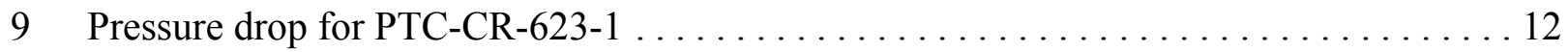

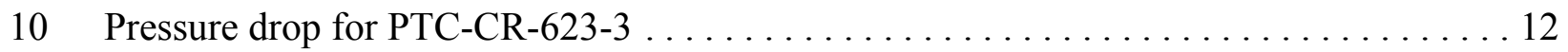

11 Bag-cleaning interval for PTC-CR-623-1 $\ldots \ldots \ldots \ldots \ldots \ldots \ldots \ldots \ldots \ldots \ldots \ldots \ldots$

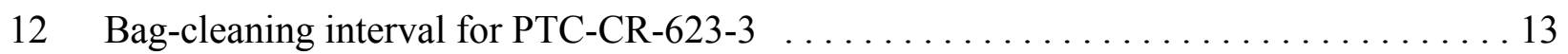

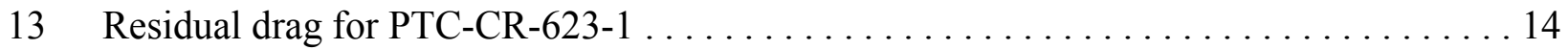

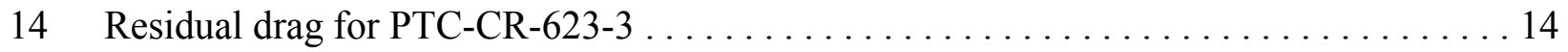

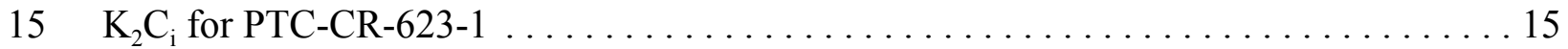

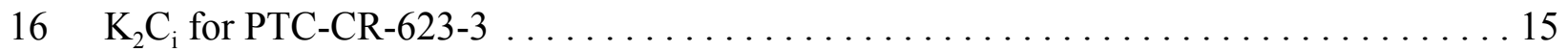

17 Effect of corona current on respirable mass in AHPC $\ldots \ldots \ldots \ldots \ldots \ldots \ldots \ldots$ 


\section{LIST OF TABLES}

1 Experimental Parameters for the AHPC Pilot Test $\ldots \ldots \ldots \ldots \ldots \ldots \ldots \ldots$

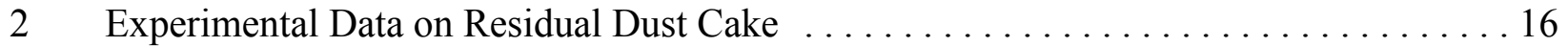

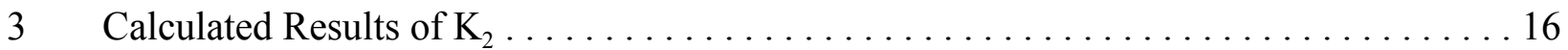

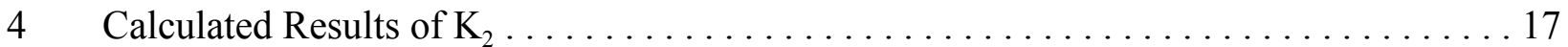




\section{ADVANCED HYBRID PARTICULATE COLLECTOR - PILOT-SCALE TESTING}

\section{EXECUTIVE SUMMARY}

A new concept in particulate control, called an advanced hybrid particulate collector (AHPC), is being developed at the Energy \& Environmental Research Center (EERC) with U.S. Department of Energy (DOE) funding. In addition to DOE and the EERC, the project team includes W.L. Gore \& Associates, Inc., Allied Environmental Technologies, Inc., and the Big Stone power station. The AHPC combines the best features of electrostatic precipitators (ESPs) and baghouses in a unique approach to develop a compact but highly efficient system. Filtration and electrostatics are employed in the same housing, providing major synergism between the two collection methods, both in the particulate collection step and in the transfer of dust to the hopper. The AHPC provides ultrahigh collection efficiency, overcoming the problem of excessive fine-particle emissions with conventional ESPs, and solves the problem of reentrainment and re-collection of dust in conventional baghouses.

The objective of the AHPC is to provide $>99.99 \%$ particulate collection efficiency for particle sizes from 0.01 to $50 \mu \mathrm{m}$ and be applicable for use with all U.S. coals at a lower cost than existing technologies.

In previous field tests with the AHPC, some minor bag damage was observed that appeared to be caused by electrical effects. Extensive studies were then carried out to determine the reason for the bag damage and to find possible solutions without compromising AHPC performance. The best solution to prevent the bag damage was found to be perforated plates installed between the electrodes and the bags, which can block the electric field from the bag surface and intercept current to the bags. The perforated plates not only solve the bag damage problem, but also offer many other advantages such as operation at higher $\mathrm{A} / \mathrm{C}$ (air-to-cloth) ratios, lower pressure drop, and an even more compact geometric arrangement.

For this project, AHPC pilot-scale tests were carried out to understand the effect of the perforated plate configuration on bag protection and AHPC overall performance and to optimize the perforated plate design. Five different perforated plate configurations were evaluated in a coal combustion system. The AHPC performed extremely well even at a low current level (1.5-3.0 mA) and a low pulse trigger pressure of $6.5 \mathrm{in}$. W.C. (1.62 kPa), resulting in a bag-cleaning interval of over $40 \mathrm{~min}$ at an $\mathrm{A} / \mathrm{C}$ ratio of $12 \mathrm{ft} / \mathrm{min}(3.7 \mathrm{~m} / \mathrm{min})$ for most of the test period. The longest bag-cleaning interval was $594 \mathrm{~min}$, which is the best to date. The residual drag was reduced to the range from 0.25 to 0.35 in. $\mathrm{H}_{2} \mathrm{O} / \mathrm{ft} / \mathrm{min}$, showing an excellent bag-cleaning ability under the perforated plate configurations. The $\mathrm{K}_{2} \mathrm{C}_{\mathrm{i}}$ at the current level of $3 \mathrm{~mA}$ was as low as 1.0, indicating excellent ESP performance. All the results are the best achieved to date. 


\section{ADVANCED HYBRID PARTICULATE COLLECTOR - PILOT-SCALE TESTING}

\section{INTRODUCTION}

This project was funded under the U.S. Department of Energy-Energy \& Environmental Research Center (EERC) Jointly Sponsored Cooperative Agreement No. DE-FC26-98FT40321, with cofunding from W.L. Gore \&Associates, Inc.

Advanced hybrid particulate collector (AHPC) development was initiated in 1994, with the objective to develop a highly reliable AHPC that can provide $>99.99 \%$ particulate collection efficiency for all particle sizes from 0.01 to $50 \mu \mathrm{m}$ and be applicable for use with all U.S. coals at a lower cost than existing technologies. This goal has remained unchanged since the concept was originally proposed in 1994. The approach objective with the AHPC is to utilize filtration and electrostatic mechanisms in a unique manner that is superior to conventional fabric filters and electrostatic precipitators (ESPs).

In the AHPC concept, the pulse-jet filter bags are installed between the grounded electrostatic collection plates and the high-voltage discharging electrodes. As the flue gas enters the AHPC unit, the fly ash particles immediately become charged and migrate toward the grounded collection plates. Because of the high electrical migration velocity (depending on particle size, charge on particles, and electric field strength), most fly ash particles are collected on the electrostatic collection plates. The remaining charged particles flow to the GORE-TEX ${ }^{\circledR}$ membrane filter bags and are captured, with an ultrahigh collection efficiency. The accumulated fly ash particles on the filter bag will change the pressure drop across the fabric filter, which is a very important operating parameter. For viscous flow, the pressure drop across fiber filters is:

$$
\mathrm{dP}=\mathrm{K}_{\mathrm{f}} \mathrm{V}+\mathrm{K}^{\prime}{ }_{2} \mathrm{~W}_{\mathrm{R}} \mathrm{V}+\mathrm{K}_{2} \mathrm{C}_{\mathrm{i}} \mathrm{V}^{2} \mathrm{t} / 7000
$$

where:

$$
\begin{aligned}
& \mathrm{dP}=\text { differential pressure across baghouse tube sheet (in. W.C.) } \\
& \mathrm{K}_{\mathrm{f}}=\text { fabric resistance coefficient (in. W.C.-min/ft) } \\
& \mathrm{V}=\text { face velocity or } \mathrm{A} / \mathrm{C} \text { ratio }(\mathrm{ft} / \mathrm{min}) \\
& \mathrm{K}_{2}{ }_{2}=\text { specific residual dust cake resistance coefficient (in. W.C.-ft-min/lb) } \\
& \mathrm{K}_{2}=\text { specific dust cake resistance coefficient (in. W.C.-ft-min/lb) } \\
& \mathrm{W}_{\mathrm{R}}=\text { residual dust cake weight }\left(\mathrm{lb} / \mathrm{ft}^{2}\right) \\
& \mathrm{C}_{\mathrm{i}}=\text { inlet dust loading (grains/acf) } \\
& \mathrm{t}=\text { filtration time between bag cleaning (min) }
\end{aligned}
$$

The first term in Equation 1 accounts for the pressure drop across the fabric. The GORE-TEX ${ }^{\circledR}$ membrane filter media allows for a pressure drop across the fabric of $1.5 \mathrm{in}$. W.C. $(0.37 \mathrm{kPa})$ at an A/C (air-to-cloth) of $12 \mathrm{ft} / \mathrm{min}(3.7 \mathrm{~m} / \mathrm{min})$. 
The second term in Equation 1 accounts for the pressure drop contribution from the permanent residual dust cake that exists on the surface of the fabric. For operation at high $\mathrm{A} / \mathrm{C}$ ratios, the bag cleaning must be sufficient to maintain a very light residual dust cake and ensure that the pressure drop contribution from this term is reasonable. The contribution to pressure drop from this term is one of the most important indicators of longer-term bag cleanability.

The third term in Equation 1 accounts for the pressure drop contribution from the dust accumulated on the bags since the last bag cleaning. $\mathrm{K}_{2}$ is determined primarily by the fly ash particle-size distribution and the porosity of the dust cake. Typical $\mathrm{K}_{2}$ values for a full dust loading of pulverized coal-fired fly ash range from about 4 to $20 \mathrm{in.} \mathrm{W.C.-ft-min/lb} \mathrm{but} \mathrm{may,} \mathrm{in} \mathrm{extreme}$ cases, cover a wider range.

The residual cake on the filter bag surface, usually in a more porous structure because of the charge on the fly ash particles, is periodically removed by a reverse pulse of compressed air with sufficient energy and volume. The fly ash particles are propelled into the ESP zone where they are charged and collected on the plate, which prevents reentrainment to the filter bags.

For Phase III, the field AHPC unit was successfully started up in April 2000 and was operated for a period of about 3 months through July 2000 . Additional testing with the $200-\mathrm{acfm}\left(5.7-\mathrm{m}^{3} / \mathrm{min}\right)$ AHPC at the EERC was also completed from August through October to evaluate electrode design and geometric spacing. Details of these results were discussed in the April-June and July-September 2000 Quarterly Technical Progress Reports $(1,2)$. As mentioned in the reports, some bag damage was noted in the tests at Big Stone that appeared to be electrical in nature.

To evaluate the cause of the bag damage observed, experiments were completed at the EERC to investigate the interactions between electrostatics and bags under different operating conditions. Results from these tests showed that there were several options to solve the bag damage problem, as detailed in the July-September Quarterly Report. However, more recent tests at the EERC conducted in October showed that one of the revised configurations produced results far better than any other tests. Our previous best pulse interval at an $\mathrm{A} / \mathrm{C}$ ratio of $12 \mathrm{ft} / \mathrm{min}(3.7 \mathrm{~m} / \mathrm{min})$ was about $30 \mathrm{~min}$ at the end of $100 \mathrm{hr}$. Here, a remarkable 3-hr and 15-min bag-cleaning interval has been achieved at the end of $100 \mathrm{hr}$ under the new configuration. It should be noted that anything over $10 \mathrm{~min}$ is considered acceptable, but any extension in the pulse interval time makes the AHPC much more attractive technically and economically. This new configuration not only appears to be the best solution to solve the bag damage problem, but also to offer many other advantages such as operation at higher $\mathrm{A} / \mathrm{C}$ ratios, lower pressure drop, and an even more compact geometric arrangement. In summary, this new configuration is a major improvement in the AHPC. However, additional pilotscale testing with the 200-acfm AHPC was necessary to refine this technology.

\section{PLANNED WORK}

For these tests, grounded perforated plates were placed between the filter bags and the discharging electrodes (as shown in Figure 1) in the pilot AHPC system. The installed grounded perforated plates not only significantly reduced the electric field strength around the bags, but also 


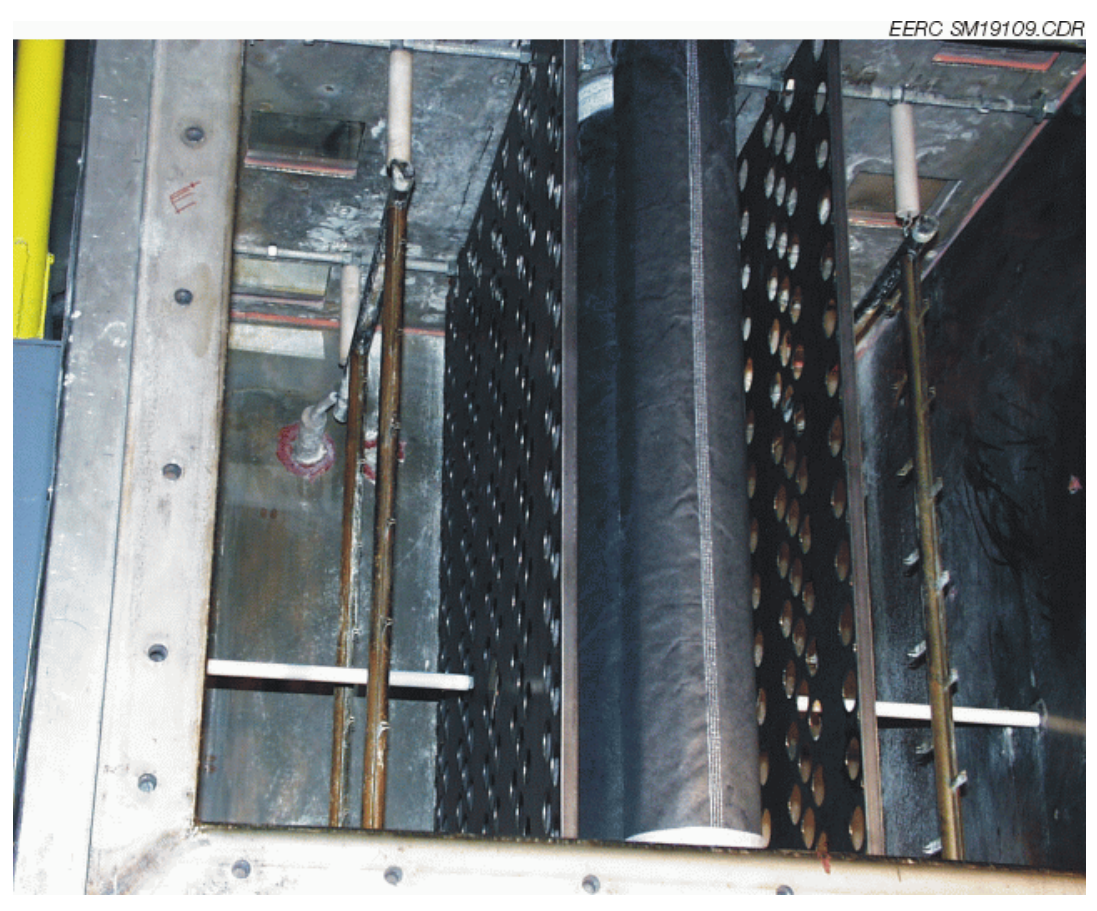

Figure 1. AHPC pilot-scale configuration at the EERC.

served as collection plates to remove fly ash from flue gas. The charged fly ash particles were precipitated on the perforated plates, which dramatically reduced the dust loading to the filter bags.

The pilot-scale experiments were systematically designed and performed to investigate the effect of perforated plates on the AHPC overall performance. Different perforated plates, in terms of hole size and opening area percentage, were selected and evaluated in the coal combustion system. The spacing from the perforated plates to bags (PTB) was varied to examine its effect on bag protection and AHPC performance. Three different bags manufactured by W.L. Gore \& Associates, Inc., are as follows:

- $\quad$ GORE-TEX $^{\circledR}$ membrane/GORE-TEX ${ }^{\circledR}$ felt filter bag

- $\quad$ GORE-NO STAT ${ }^{\circledR}$ filter bag (GORE-TEX ${ }^{\circledR}$ membrane/GORE-TEX $^{\circledR}$ felt)

- $\quad$ GORE-NO STAT ${ }^{\circledR}$ filter bag $\left(\right.$ GORE-TEX ${ }^{\circledR}$ antistatic membrane/GORE-TEX ${ }^{\circledR}$ felt)

These bags were used with different electrodes, i.e., bidirectional ELEX-2-Mast, directional ELEX2-Mast, and directional ELEX-with mast-only second electrode, to evaluate their performance under different configurations. The operating parameters such as corona current, pulse trigger pressure, and dust loading were also varied. A summary of the variables tested in the pilot-scale experiments is listed below. 


\section{Bag Types}

- $\quad$ GORE-TEX $^{\circledR}$ membrane/GORE-TEX $^{\circledR}$ felt filter bag

- $\quad$ GORE-NO STAT ${ }^{\circledR}$ filter bag (GORE-TEX ${ }^{\circledR}$ membrane/GORE-TEX $^{\circledR}$ felt)

- $\quad$ GORE-NO STAT ${ }^{\circledR}$ filter bag (GORE-TEX ${ }^{\circledR}$ antistatic membrane/GORE-TEX ${ }^{\circledR}$ felt)

\section{Perforated Plates}

- $\quad$ Hole size $(\mathrm{ID}=1.5-2.0 \mathrm{in}$. $[0.038-0.051 \mathrm{~m}])$

- $\quad$ Opening area $(48 \%-52 \%)$

- $\quad$ Geometric alignment $(\mathrm{PTB}=2.0-3.0$ in. $[0.051-0.076 \mathrm{~m}])$

\section{Electrodes}

- $\quad$ Bidirectional ELEX-2-Mast

- Directional ELEX-2-Mast

- Directional ELEX-Mast-only second

\section{Operating Conditions}

- $\quad$ Current (0-3.0 mA)

- Pulse trigger pressure $\left(6.5-8.0\right.$ in. $\left.\mathrm{H}_{2} \mathrm{O}\right)$ [1.65-2.0 $\left.\mathrm{kPa}\right]$

To quantitively evaluate the effect of the perforated plate on bag protection, the currents to the bags were measured under the different perforated plate configurations for the three different bags. The current meters were used to monitor the current to the bags during the hot coal combustion tests. Secondary current and voltage, bag-cleaning interval, and tube sheet pressure drop were measured. The results provided detailed engineering data for further optimization of the AHPC system.

\section{AHPC PILOT TESTING RESULTS}

A total of five configurations were selected and evaluated in the hot-flow coal combustion tests. These tests are designated PTC-CR-622-1 through PTC-CR-622-3 and PTC-CR-623-1 and PTC-CR-623-3, where the CR designation is for the Cordero Rojo complex coal used for the tests. Two GORE-NO STAT ${ }^{\circledR}$ filter bags (GORE-TEX ${ }^{\circledR}$ antistatic membrane/GORE-TEX ${ }^{\circledR}$ felt), one GORE-NO STAT $^{\circledR}$ filter bag $\left(\right.$ GORE-TEX $^{\circledR}$ membrane/GORE-TEX $^{\circledR}$ felt), and one GORE-TEX ${ }^{\circledR}$ membrane/GORE-TEX ${ }^{\circledR}$ felt filter bag were installed in the AHPC pilot unit to examine bag protection and their performance in the modified configuration. The detailed experimental parameters are listed in Table 1.

The bidirectional ELEX-2-Mast electrodes used in PTC-CR-622-1 forced the fly ash particles to migrate both to the perforated plates and wall surface of the AHPC vessel because of the uniformly distributed electric field within the AHPC chamber generated by the bidirectional electrode tips. The directional-ELEX-2-Mast electrodes were then used in the following experiments 
TABLE 1

Experimental Parameters for the AHPC Pilot Test

\begin{tabular}{|c|c|c|c|c|}
\hline Test No. & $\begin{array}{c}\text { Duration, } \\
\mathrm{hr}\end{array}$ & Electrode & $\mathrm{PTB}^{1}$ & Plate Type \\
\hline PTC-CR-622-1 & 24 & Bidirectional ELEX-2-Mast & 2.0 & $\begin{array}{l}1.5 \text { in. }(0.038 \mathrm{~m}), 48 \% \\
\text { open }\end{array}$ \\
\hline PTC-CR-622-2 & 35 & Directional ELEX-2-Mast & 2.0 & $\begin{array}{l}1.5 \text { in. }(0.038 \mathrm{~m}), 48 \% \\
\text { open }\end{array}$ \\
\hline PTC-CR-622-3 & 40 & Directional ELEX-2-Mast & 2.0 & $\begin{array}{l}2.0 \mathrm{in} .(0.051 \mathrm{~m}), 52 \% \\
\text { open }\end{array}$ \\
\hline PTC-CR-623-1 & 54 & Directional ELEX-2-Mast & 3.0 & $\begin{array}{l}1.5 \text { in. }(0.038 \mathrm{~m}) \text {, with } \\
\text { solid section } 42 \% \text { open }\end{array}$ \\
\hline PTC-CR-623-3 & 57 & $\begin{array}{l}\text { Directional ELEX-2-Mast and } \\
\text { Directional ELEX-Mast-Only Second }\end{array}$ & 3.0 & $1.5(0.038 \mathrm{~m}), 48 \%$ open \\
\hline
\end{tabular}

${ }^{1}$ Spacing from PTB.

to minimize collection of dust on the vessel walls. Directional ELEX-Mast-only second electrodes (no electrode tips on the second mast) were used at the end of the PTC-CR-623-3 to concentrate the corona current at the AHPC inlet.

By adjusting the perforated plate position in the AHPC, the spacing between the PTB was varied from 2.0 to $3.0 \mathrm{in}$. (0.051 to $0.076 \mathrm{~m}$ ) in the tests to examine the effects on bag protection and bag-cleaning ability.

Secondary current and voltage, bag-cleaning interval, and tube sheet pressure drop were measured, and $\mathrm{K}_{2} \mathrm{C}_{\mathrm{i}}$ was calculated for all the tests. The AHPC performed extremely well even at a low current level (1.5-3.0 mA) and a low pulse trigger pressure of 6.5 in. W.C. (1.62 kPa), resulting in a bag-cleaning interval of over $40 \mathrm{~min}$ at an $\mathrm{A} / \mathrm{C}$ ratio of $12 \mathrm{ft} / \mathrm{min}(3.7 \mathrm{~m} / \mathrm{min})$ for most of the test period. The longest bag-cleaning interval was $594 \mathrm{~min}$, which is the best achieved to date. The residual drag was reduced to the range from 0.25 to $0.35 \mathrm{in} . \mathrm{H}_{2} \mathrm{O} / \mathrm{ft} / \mathrm{min}$, showing an excellent bag-cleaning ability under the perforated plate configurations. The $\mathrm{K}_{2} \mathrm{C}_{\mathrm{i}}$ at the current level of $3 \mathrm{~mA}$ was as low as 1, indicating an excellent ESP performance. The current to bag, measured for all the tests in the presence of the perforated plates, was below $1.5 \mu \mathrm{A}$ for the GORE-NO STAT ${ }^{\circledR}$ filter bag (GORE-TEX ${ }^{\circledR}$ antistatic membrane/GORE-TEX ${ }^{\circledR}$ felt) and $0.5 \mu$ A for the GORE-NO STAT ${ }^{\circledR}$ filter bag (GORE-TEX ${ }^{\circledR}$ membrane/GORE-TEX ${ }^{\circledR}$ felt), which is extremely low compared to the current to bag over $100 \mu \mathrm{A}$ at the same corona current level without perforated plates, indicating excellent bag protection in terms of reducing bag current.

\section{PTC-CR-622}

Test PTC-CR-622-1 was started (January 15-16) with an A/C ratio of $12 \mathrm{ft} / \mathrm{min}(3.7 \mathrm{~m} / \mathrm{min})$ and a pulse trigger pressure of $8.0 \mathrm{in}$. W.C. $(2.0 \mathrm{kPa})$. The perforated plates $(1.5 \mathrm{in} .[0.038 \mathrm{~m}]$, and $48 \%$ opening area) were installed. The spacing between the perforated plates and bags was set at 
2.00 in. $(0.051 \mathrm{~m})$, which provided enough protection of the bags from electrical damage and also prevented any possible contact between the bag and the plate during the bag pulsing. The bidirectional ELEX-2-Mast standard electrodes were used in the experiment. The secondary current was at $1.5 \mathrm{~mA}$ throughout the test period except for a gradual current reduction at the end of the test. The bag-cleaning interval (shown in Figure 2) was initially at $120 \mathrm{~min}$ and then dropped and remained steady around $100 \mathrm{~min}$ after $24 \mathrm{hr}$ of testing. The residual drag plotted as a function of running time in Figure 3 was in the range of 0.25 to $0.35 \mathrm{in} . \mathrm{H}_{2} \mathrm{O} / \mathrm{ft} / \mathrm{min}$ during the test, indicating an excellent bag-cleaning ability even at a relatively low current level of $1.5 \mathrm{~mA}$. However, it is noted that the residual drag might climb in the long-term operation. The calculated $\mathrm{K}_{2} \mathrm{C}_{\mathrm{i}}$ (in Figure 4) remained at a value of 2 during the test when the current was only $1.5 \mathrm{~mA}$, showing that the ESP functioned extremely well at the low current in the perforated plate configuration. The high-voltage power was shut down at the end of Test PTC-CR-622-1 to examine the perforated plate AHPC performance under a conventional baghouse operation mode. Without the presence of corona and electric field, the fast accumulation of fly ash on the filter bags resulted in a dramatic increase of $\mathrm{K}_{2} \mathrm{C}_{\mathrm{i}}$ up to 22 (Figure 4), indicating no electrostatic precipitation occurred. Also, the bag-cleaning interval was reduced to $7 \mathrm{~min}$ with a relative higher residual drag of $0.4 \mathrm{in} . \mathrm{H}_{2} \mathrm{O} / \mathrm{ft} / \mathrm{min}$. The above results not only show the enormous benefits of the synergism between the ESP and filtration within the AHPC, but also show that the AHPC could operate for short periods without ESP power. This could be very important in full-scale AHPC operation, because the AHPC could treat all of the flue gas without an increase in emissions during periods of interruption to the ESP power. The photo (Figure 5) shows ash deposition on the perforated plate. The ash deposition pattern observed was the result of the specific electrode design.

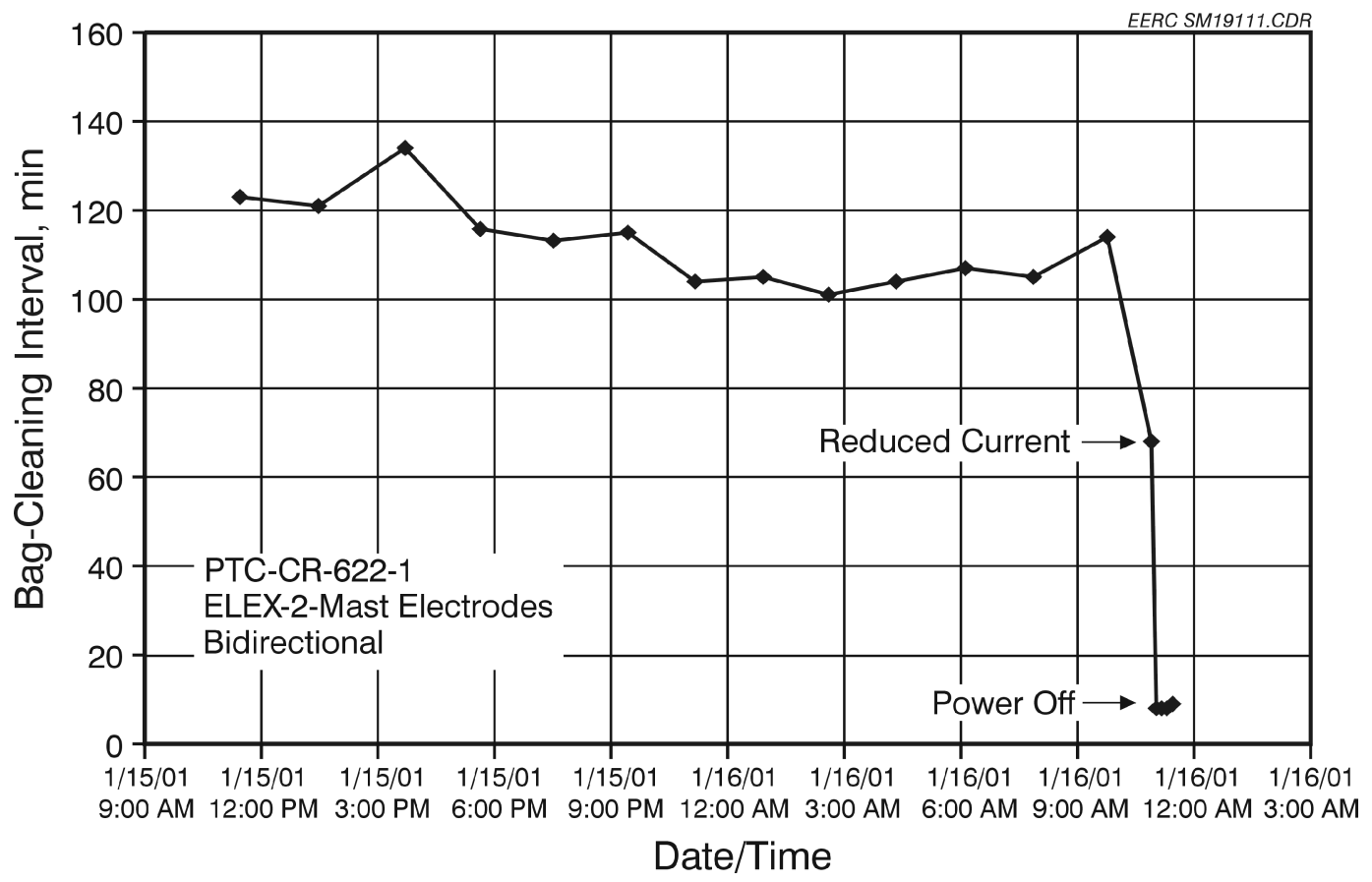

Figure 2. Bag-cleaning interval for PTC-CR-622-1. 


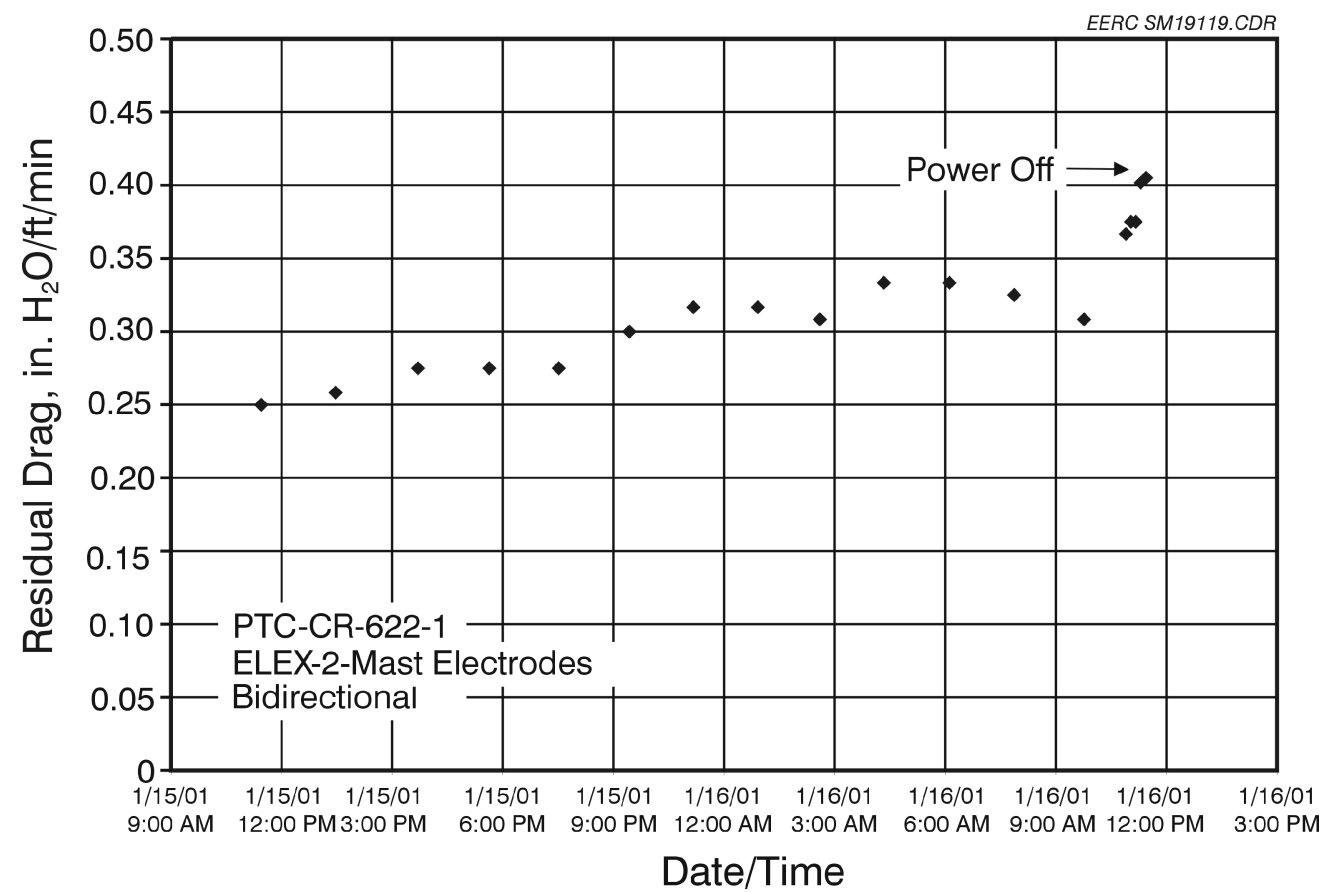

Figure 3. Residual drag for PTC-CR-622-1.

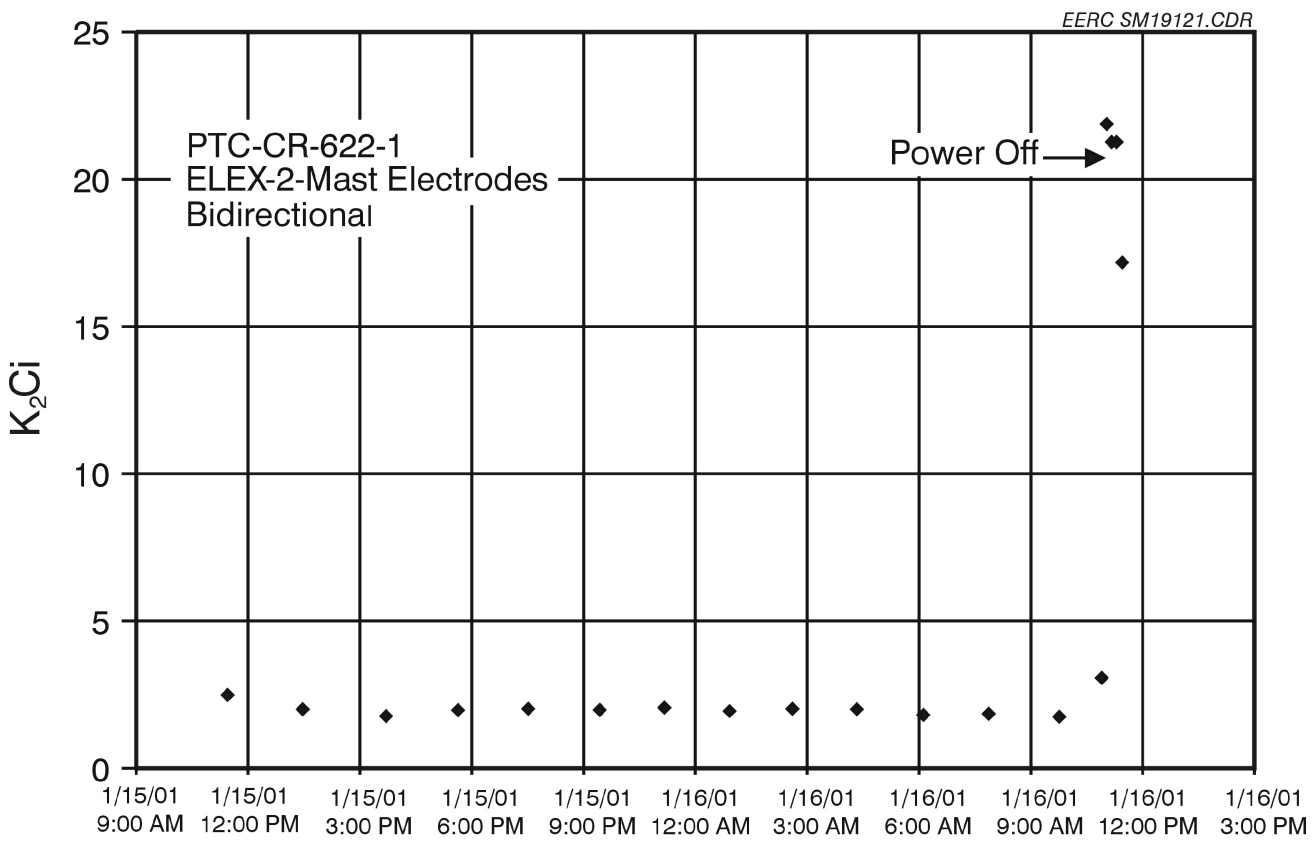

Date/Time

Figure 4. $\mathrm{K}_{2} \mathrm{C}_{\mathrm{i}}$ for PTC-CR-622-1. 


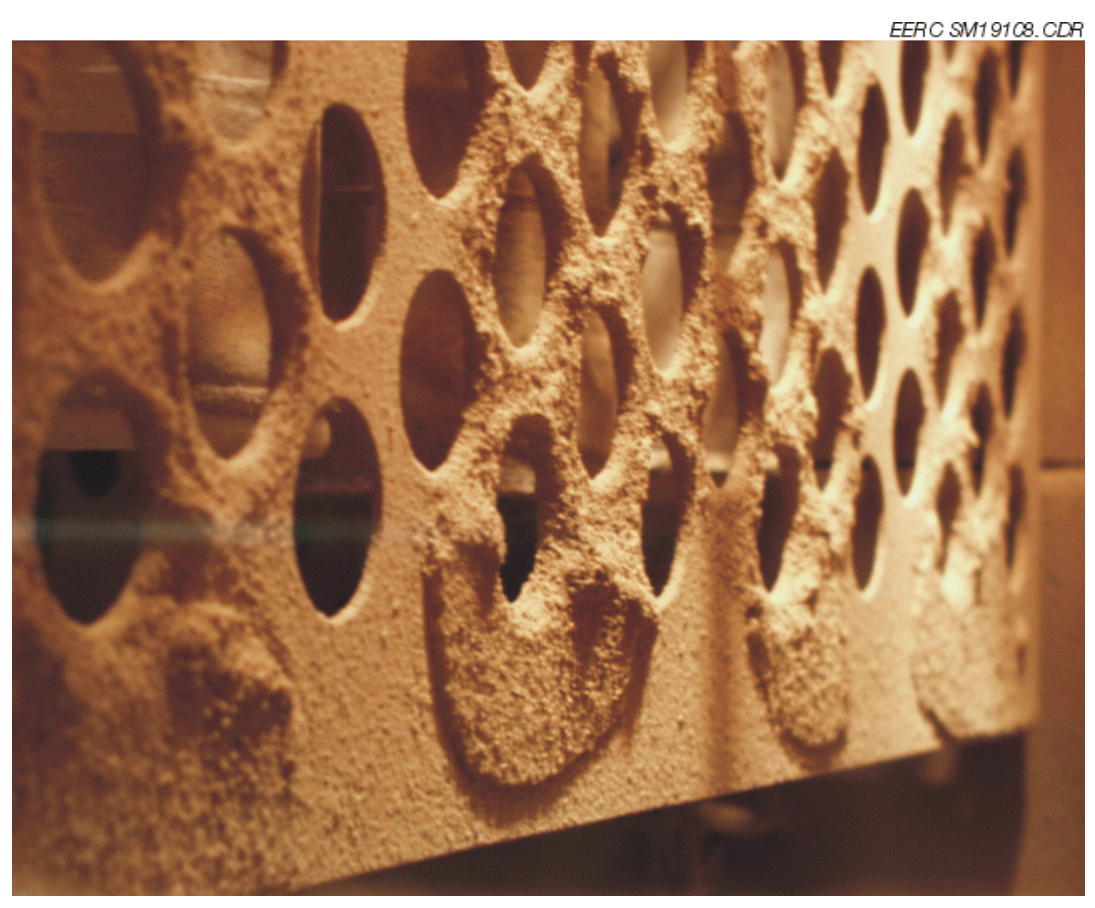

Figure 5. Fly ash-deposited pattern on the perforated plates at the pilot-scale AHPC.

Tests PTC-CR-622-2 (35 hr) and PTC-CR-622-3 (40 hr) were carried out to examine the AHPC performance under two different perforated plate designs: 1.5-in. (0.038-m) hole size and 2.0in. $(0.051-\mathrm{m})$ hole size. The directional ELEX-2-Mast electrodes instead of the bidirectional ELEX2-Mast electrode were used to force more fly ash to migrate toward the perforated plates rather than the outside walls of the vessel. The secondary current was increased to $3.0 \mathrm{~mA}$ during the two test periods except during Run Hours 18 to 23 when current level was reduced to $1.5-0.5 \mathrm{~mA}$ to investigate the corresponding AHPC performance. The bag-cleaning intervals plotted and shown in Figure 6 were initially 375 min for PTC-CR-622-2 and 594 min for PTC-CR-622-3, respectively, which were the longest bag-cleaning intervals achieved by far. The bag-cleaning interval dropped to $205 \mathrm{~min}$ (PTC-CR-622-2) and $280 \mathrm{~min}$ (PTC-CR-622-3) at the end of the tests due to bag seasoning. The observed bag-cleaning intervals of less than $100 \mathrm{~min}$ in the middle of the experiments were due to the lower current level at that time. The improved bag-cleaning intervals in the two tests compared to the data in PTC-CR-622-1 are attributed to the higher current level, resulting in better ESP performance which is also reflected in $\mathrm{K}_{2} \mathrm{C}_{\mathrm{i}}$ shown in Figure 7. The $\mathrm{K}_{2} \mathrm{C}_{\mathrm{i}}$ at the current level of $3 \mathrm{~mA}$ was as low as 1.0 at the end of the test, which is the best achieved to date. The residual drag (Figure 8) during the two tests was maintained less than 0.3 in. $\mathrm{H}_{2} \mathrm{O} / \mathrm{ft} / \mathrm{min}$ at the end of the experiments, demonstrating better cleaning ability in the two configurations than that in PTC-CR622-1, partially due to the better ESP performance at the higher current level. PTC-CR-622-3 showed better performance than PTC-CR-622-2 in terms of the longer bag-cleaning interval and the lower residual drag even though they almost were in the same operating conditions - pulse trigger pressure, current level, and A/C ratio - implying the 2.0-in. (0.051-m) hole perforated plate design might be the better option in improving AHPC overall performance. However, there was concern 


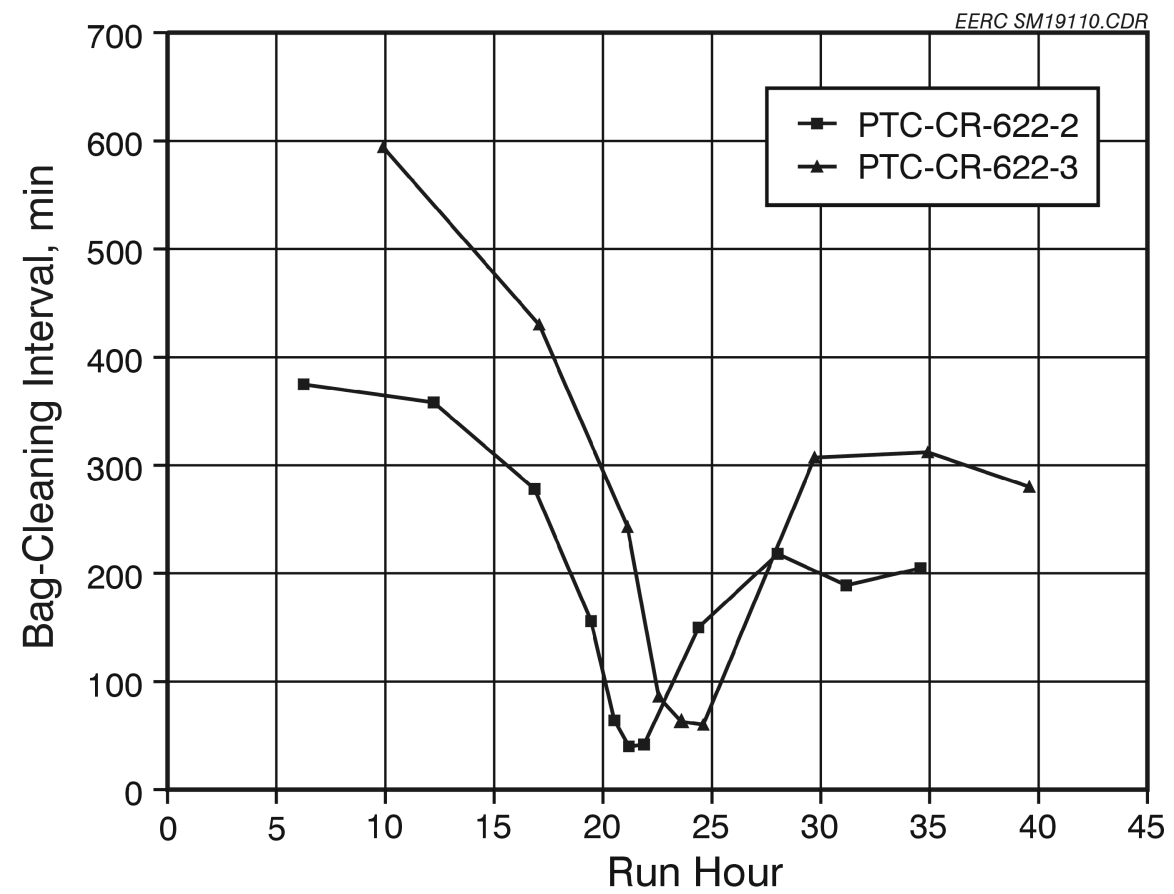

Figure 6. Bag-cleaning intervals for PTC-CR-622-2 and PTC-CR-622-3.

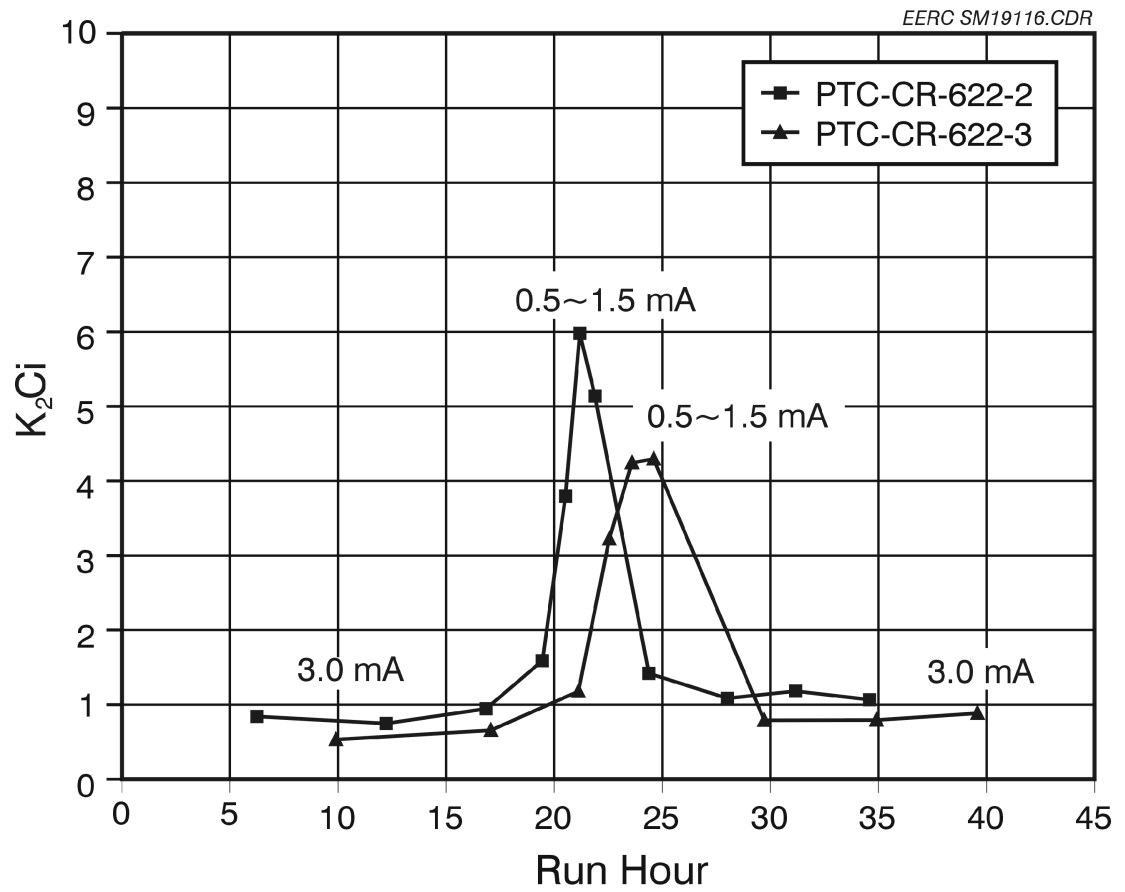

Figure 7. $\mathrm{K}_{2} \mathrm{C}_{\mathrm{i}}$ for PTC-CR-622-2 and PTC-CR-622-3. 


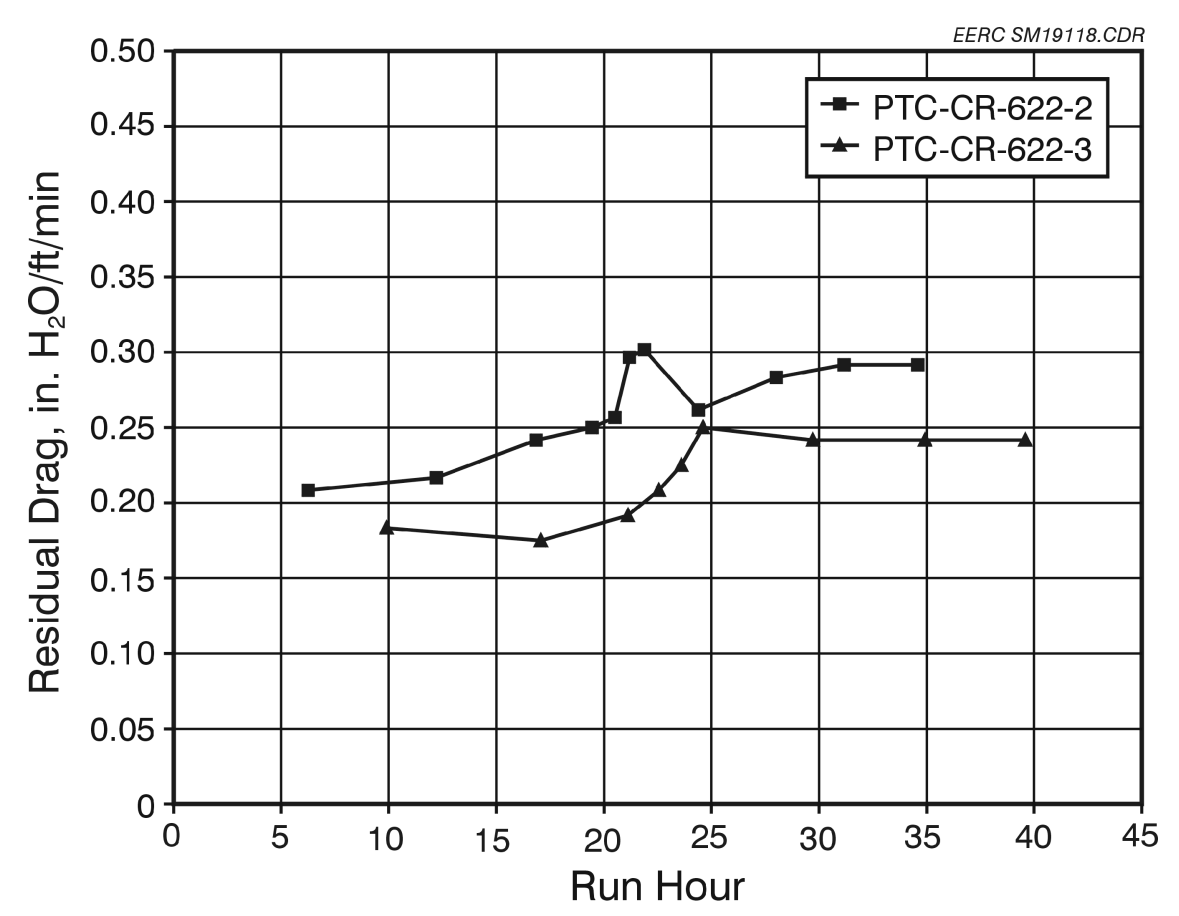

Figure 8. Residual drag for PTC-CR-622-2 and PTC-CR-622-3.

that the 2.0-in. $(0.051-\mathrm{m})$ hole size may not provide bag protection as good as the 1.5 -in $(0.038-\mathrm{m})$ hole size.

The PTC-CR-622 series experiments were exceptionally successful, achieving long bag-cleaning interval, low residual drag, and reasonable power consumption. All the results show the perforated plate design can not only protect the bag from electrically induced damage, but also substantially improve the AHPC overall performance.

\section{PTC-CR-623}

The perforated plate design was then modified in an effort to provide better protection of the bags. The hole pattern on the perforated plate was changed so that the plate section directly opposite of the bags was solid to reduce the electric field around the bag surface and current to the bags. PTCCR-623-1 (1.5-in. [0.038-m] hole with solid section) and PTC-CR-623-3 (1.5-in. [0.038-m] hole without solid section) were then carried out from February 5 to 10 to test the AHPC performance under the new configurations. The directional ELEX-Mast-only second electrodes were used at the end of Test PTC-CR-623-3 to optimize the electric field within the AHPC vessel by concentrating corona current at the AHPC inlet. The perforated plates were also moved closer to the electrodes so the spacing from the perforated plate to the bag surface was increased to $3.0 \mathrm{in}$. $(0.076 \mathrm{~m})$ to examine its effect on bag protection. Experiments were then performed to evaluate AHPC overall performance under the modified configurations. Other parameters such as current and pulse trigger pressure were also tested during the two experiments. Current was $1.5 \mathrm{~mA}$ except for short-term lowcurrent-level $(0.5-0.75-\mathrm{mA})$ tests. The tube sheet pressure drop is plotted as a function of time and 
shown in Figures 9 and 10 for PTC-CR-623-1 and PTC-CR-623-3, respectively. The pulse trigger pressure was reduced to $6.5 \mathrm{in}$. W.C. $(1.62 \mathrm{kPa})$ in the short term. Additional fly ash was injected into the system during the test period 14:23-18:13, 02/09/01, for Test PTC-CR-623-3 to examine AHPC performance under a high dust-loading environment. The supplemental dust injection resulted in an extremely high dust loading of 22.8 grain/scf in the AHPC vessel which was 14 times the baseline loading.

The resultant bag-cleaning interval, residual drag, and $\mathrm{K}_{2} \mathrm{C}_{\mathrm{i}}$ are plotted in Figures 11-16 for the two tests. Figures 11 and 12 show the bag-cleaning interval dropped to about half the previous level when the current and trigger pressure were reduced. The observed shorter bag-cleaning interval of 18 min in PTC-CR-623-3, caused by the high dust loading, is still encouraging because anything over $10 \mathrm{~min}$ is considered acceptable under a high $\mathrm{A} / \mathrm{C}$ ratio of $12 \mathrm{ft} / \mathrm{min}(3.7 \mathrm{~m} / \mathrm{min})$. The residual drag (Figures 13 and 14) only increased slightly at a low trigger pulse pressure and low current levels, which is highly encouraging because it shows that there is a wide margin to reduce power consumption and still maintain a long bag-cleaning interval and excellent bag-cleaning ability. The calculated $\mathrm{K}_{2} \mathrm{C}_{\mathrm{i}}$ (Figures 15 and 16) shows its strong dependence on current level, and a higher current results in a lower $\mathrm{K}_{2} \mathrm{C}_{\mathrm{i}}$, indicating better ESP performance. The decreasing trigger pressure from 8 in. W.C. to 6.5 in. W.C. $(2.0 \mathrm{kPa}$ to $1.62 \mathrm{kPa})$, however, does not result in a significant increase of $\mathrm{K}_{2} \mathrm{C}_{\mathrm{i}}$. It is noted that, by using directional ELEX-Mast-only second electrodes instead of directional ELEX-2-Mast electrodes, there was no significant difference observed with regard to bagcleaning interval, residual drag, and $\mathrm{K}_{2} \mathrm{C}_{\mathrm{i}}$, which shows the potential of using Mast-only-type electrodes in the AHPC to improve ESP performance without deteriorating AHPC overall performance.

There were no significant differences with regard to AHPC overall performance for the two perforated plate designs (with and without solid section). Also, the adjustment of PTB to 3.0 in. $(0.076 \mathrm{~m})$ did not affect the AHPC performance. All the bags were sent back to W.L. Gore \& Associates, Inc., for analysis, and no bag damage was observed for all three types of bags.

The residual dust cake weights on the bags were determined by comparing the new bag weight measured at the beginning of the tests with the bag weight at the end of the tests. The detailed calculation is in Table 2.

The residual dust cake weight $\mathrm{W}_{\mathrm{R}}$ can be calculated as: $\mathrm{W}_{\mathrm{R}}=\mathrm{W} /\left(\pi \cdot \mathrm{d} \cdot \mathrm{L}+\pi \mathrm{d}^{2}\right)$

$$
\begin{aligned}
& \text { PTC-CR-623-1: } \mathrm{W}_{\mathrm{R}}=9.359 \times 10^{-3}\left(\mathrm{lb} / \mathrm{ft}^{2}\right) \\
& \text { PTC-CR-623-3: } \mathrm{W}_{\mathrm{R}}=7.824 \times 10^{-3}\left(\mathrm{lb} / \mathrm{ft}^{2}\right)
\end{aligned}
$$

$\mathrm{K}{ }_{2}$ was calculated based on the experimental data and listed in Table 3.

The higher value of $\mathrm{K}_{2}{ }_{2}$ in Test PTC-CR-623-3 could be the result of double pulses at the end of the experiment. 


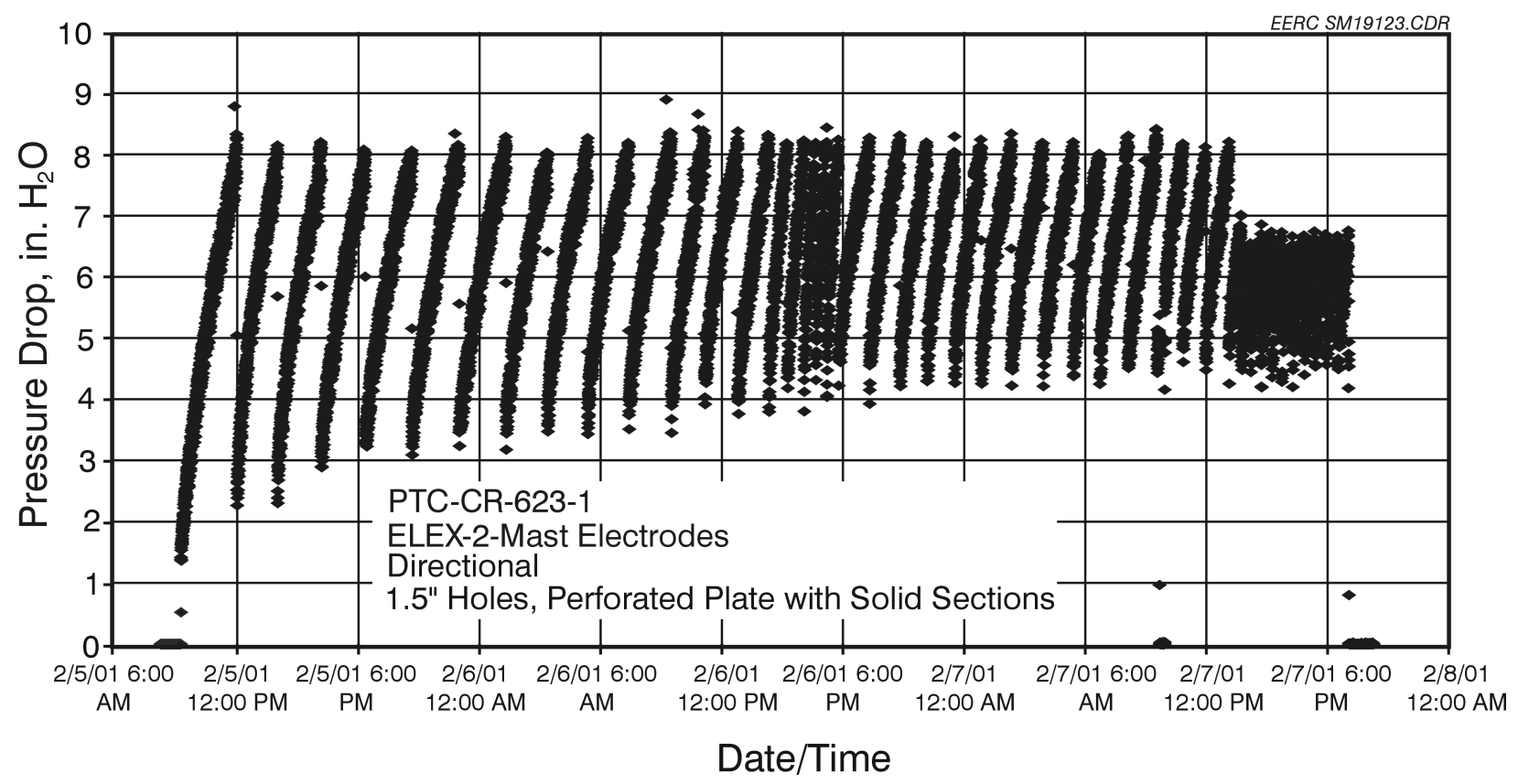

Figure 9. Pressure drop for PTC-CR-623-1.

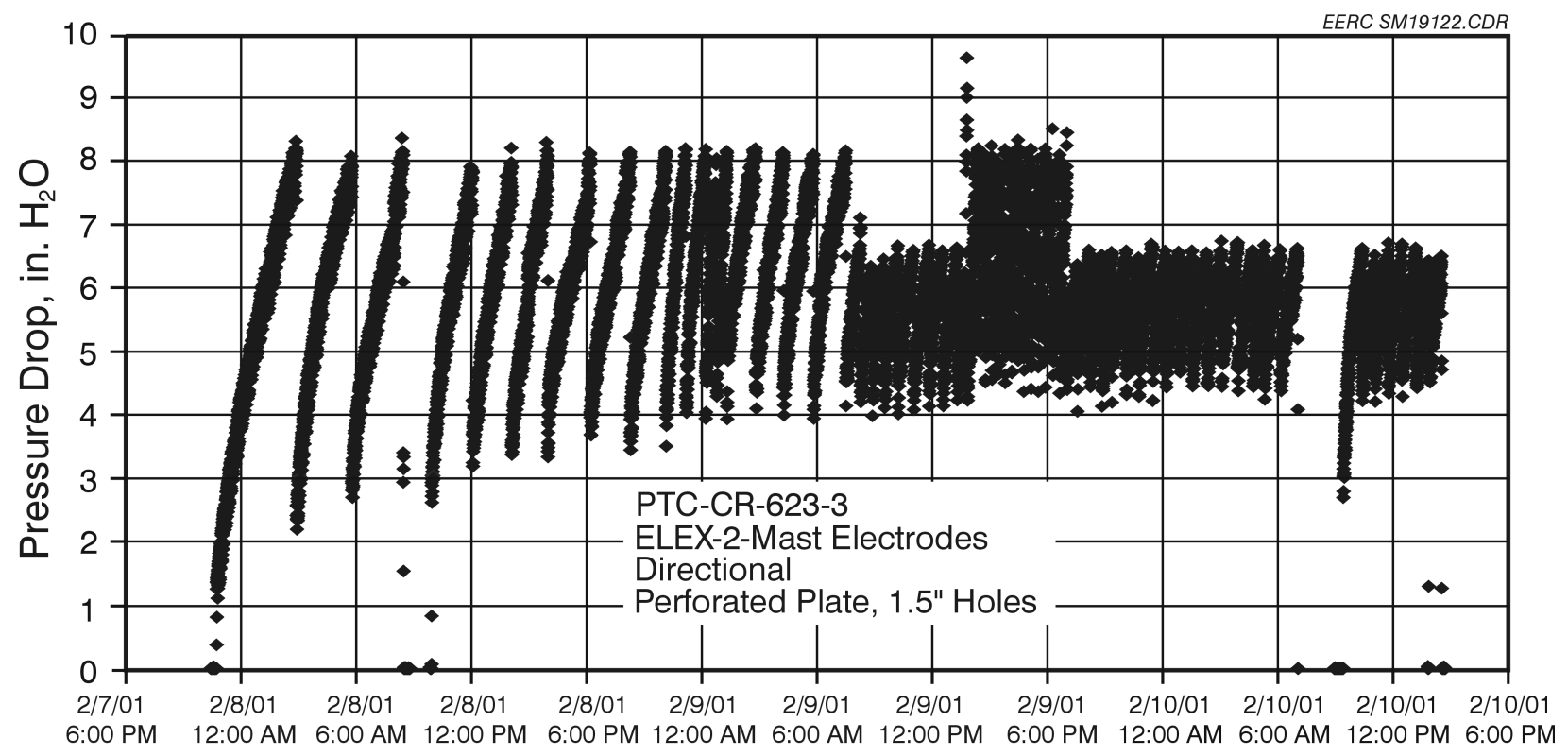
Date/Time

Figure 10. Pressure drop for PTC-CR-623-3. 


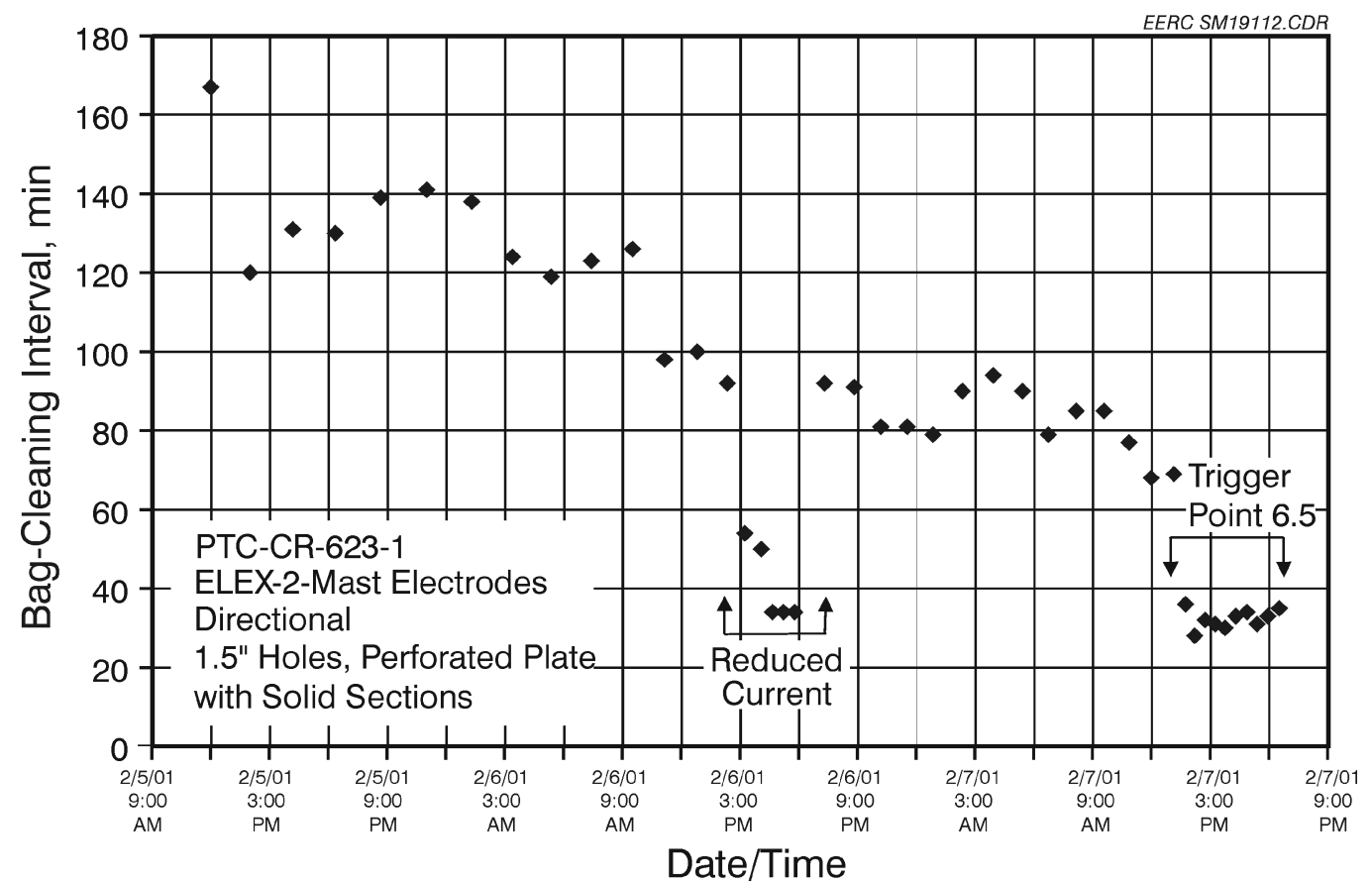

Figure 11. Bag-cleaning interval for PTC-CR-623-1.

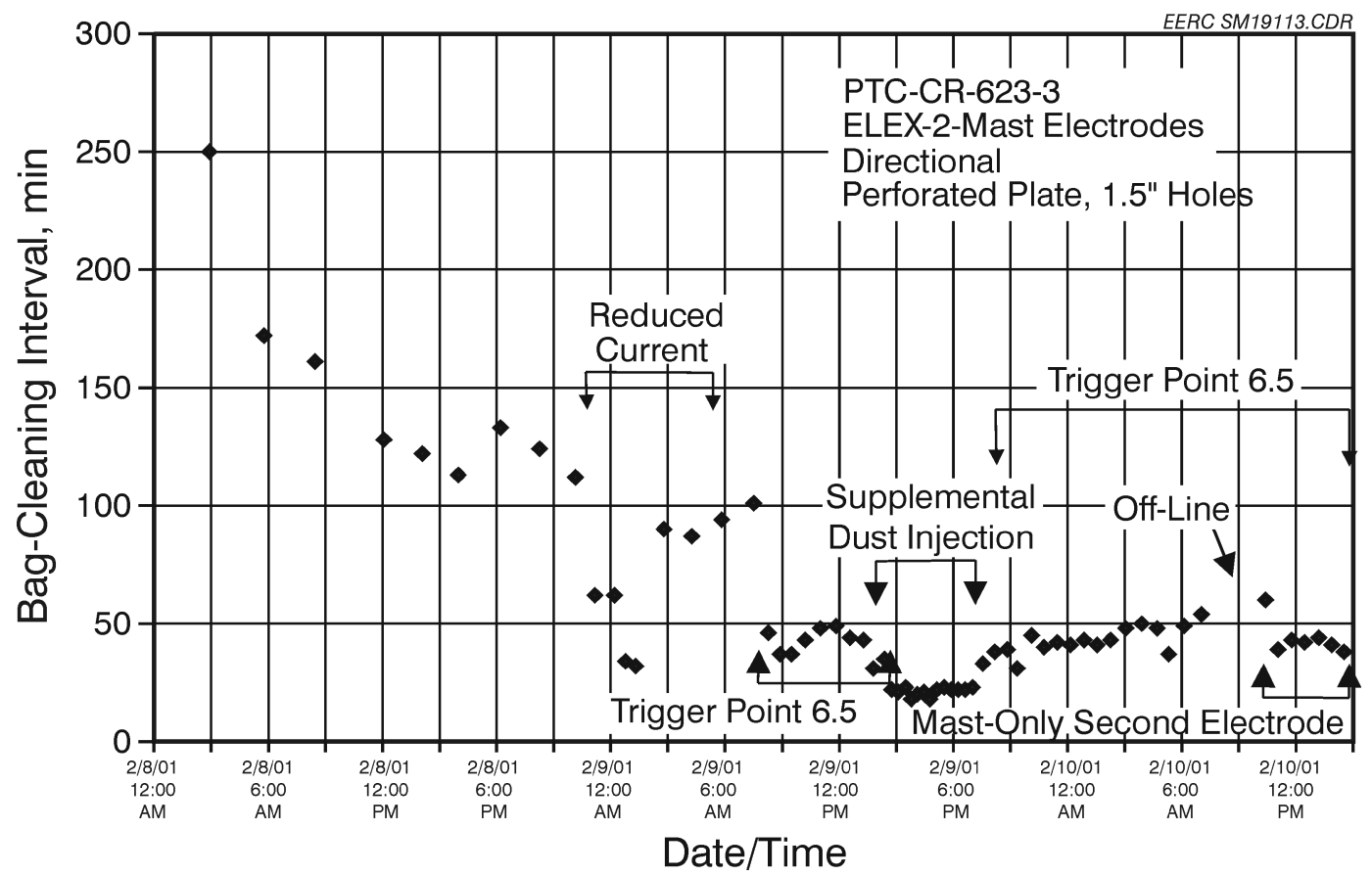

Figure 12. Bag-cleaning interval for PTC-CR-623-3. 


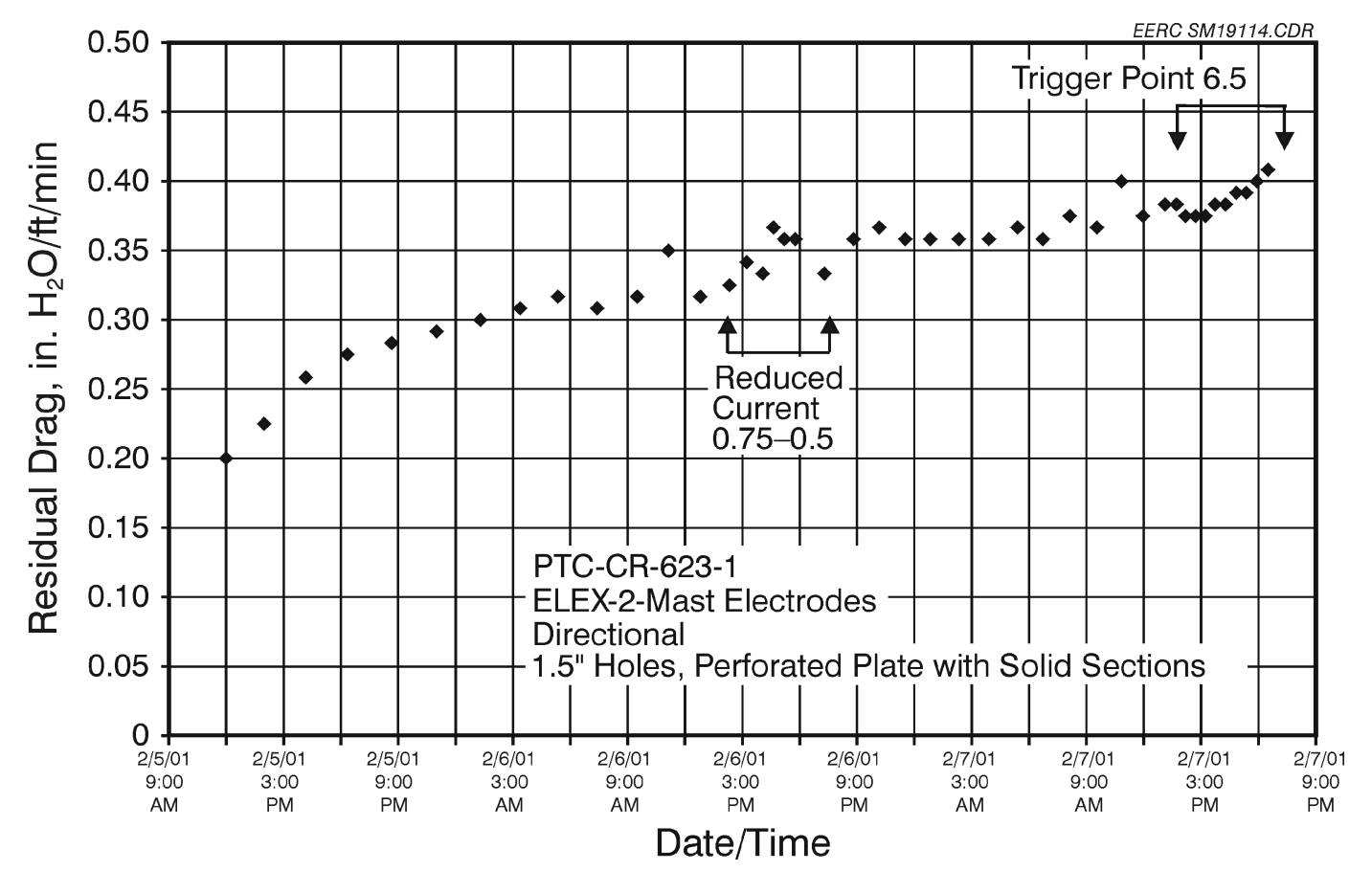

Figure 13. Residual drag for PTC-CR-623-1.

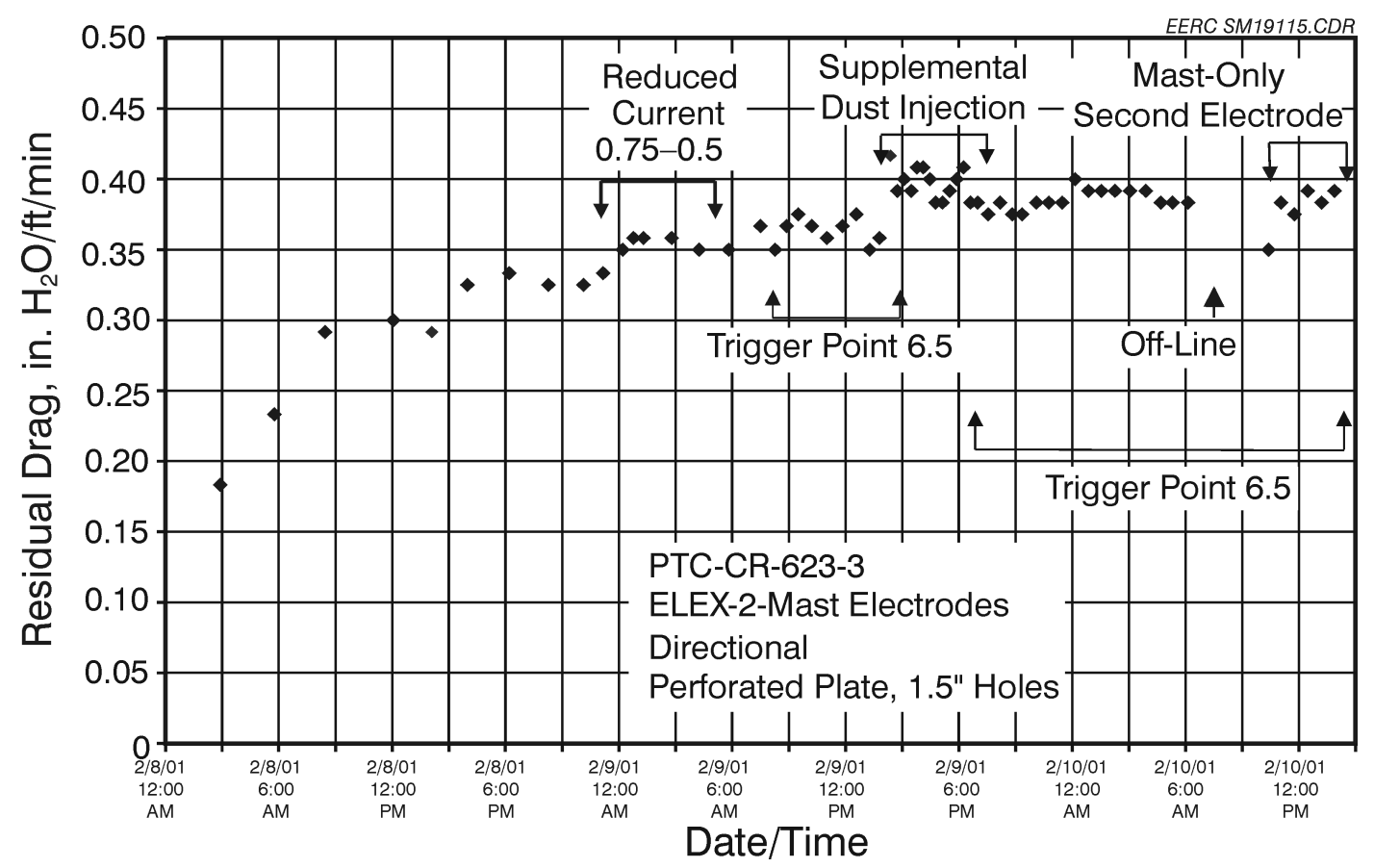

Figure 14. Residual drag for PTC-CR-623-3. 


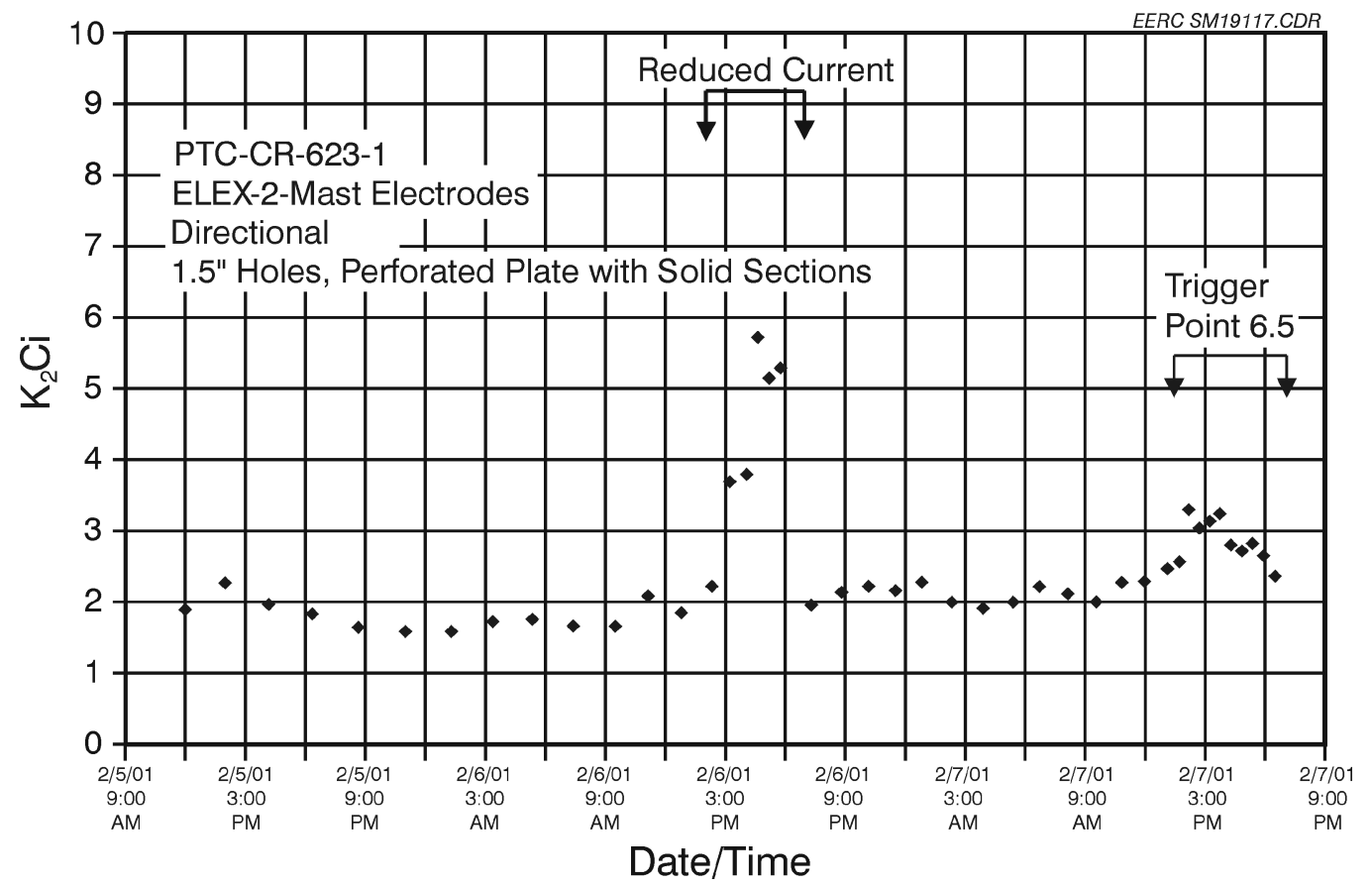

Figure $15 . \mathrm{K}_{2} \mathrm{C}_{\mathrm{i}}$ for PTC-CR-623-1.

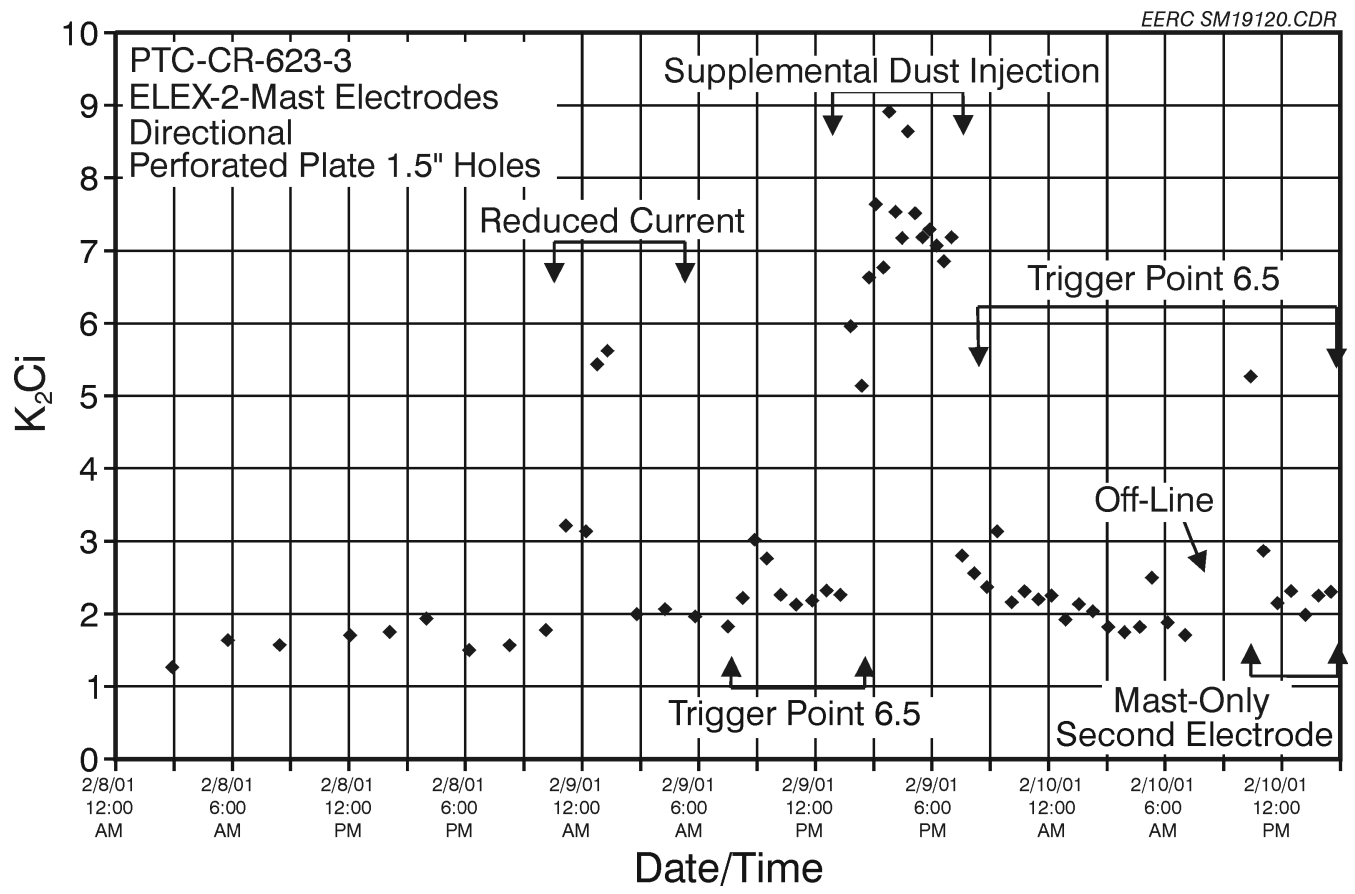

Figure 16. $\mathrm{K}_{2} \mathrm{C}_{\mathrm{i}}$ for PTC-CR-623-3. 


\section{TABLE 2}

Experimental Data on Residual Dust Cake

\begin{tabular}{lcccccc}
\hline Test No. & Bag 1, g & Bag 2, g & Bag 3, g & Bag 4, g & Average, g & Average, lb \\
\hline PTC-CR-623-1 & 20.7 & 25.2 & 14.7 & 19.0 & 19.9 & 0.0439 \\
PTC-CR-623-3 & 15.0 & 20.4 & 17.3 & 13.9 & 16.65 & 0.0367 \\
\hline
\end{tabular}

TABLE 3

Calculated Results of $\mathrm{K}_{2}$

\begin{tabular}{lcccc}
\hline Time & Running Time, $\mathrm{hr}$ & $\mathrm{K}_{2} \mathrm{C}_{\mathrm{i}}$ & $\mathrm{K}_{2}$ & Average \\
\hline PTC-CR-623-1 & & & & \\
2/7/01 13:43 & 52.5 & 2.56 & 27.6 & \\
2/7/01 14:11 & 52.9 & 3.29 & 27.6 & \\
2/7/01 14:43 & 53.5 & 3.04 & 26.7 & \\
2/7/01 15:14 & 54.1 & 3.14 & 26.7 & \\
2/7/01 15:44 & 54.5 & 3.24 & 26.7 & \\
2/7/01 16:17 & 55.1 & 2.80 & 27.6 & \\
2/7/01 16:51 & 55.6 & 2.72 & 27.6 & \\
2/7/01 17:22 & 56.2 & 2.82 & 28.5 & \\
2/7/01 17:55 & 56.7 & 2.65 & 28.5 & \\
2/7/01 18:30 & 57.3 & 2.36 & 29.4 & \\
PTC-CR-623-3 & & & & \\
2/10/01 3:04 & 52.3 & 1.82 & 34.1 & \\
2/10/01 3:54 & 53.2 & 1.75 & 34.1 & \\
2/10/01 4:42 & 53.9 & 1.82 & 34.1 & \\
2/10/01 5:19 & 54.6 & 2.50 & 33.1 & \\
2/10/01 6:08 & 55.4 & 1.88 & 33.1 & \\
2/10/01 7:02 & 56.3 & 1.71 & 33.1 & \\
\hline
\end{tabular}

During the experiments, a sampling probe was installed at the location between the perforated plates and the filter bags. The dust loading toward the filter bags was measured by U.S. Environmental Protection Agency (EPA) Method 5. The results are shown in Table 4.

It is observed that there are no significant difference between $\mathrm{K}_{2}$ and $\mathrm{K}_{2}$, implying that the dust did not penetrate into the membrane on the filter bag surface, which in conventional media can result in a significant increase in $\mathrm{K}_{2}$. 
TABLE 4

Calculated Results of $\mathrm{K}_{2}$

\begin{tabular}{lcccc}
\hline Test No. & Sampling Date and Time & $\mathrm{Ci}$, grains/scf & $\mathrm{K}_{2} \mathrm{C}_{\mathrm{i}}$ & $\mathrm{K}_{2}$ \\
\hline PTC-623-1 & $02 / 06 / 01,10: 45$ & 0.076 & 1.95 & 25.68 \\
PTC-623-3 & $02 / 08 / 01,15: 10$ & 0.064 & 1.69 & 26.55 \\
\hline
\end{tabular}

\section{EVALUATION OF ESP PERFORMANCE IN THE AHPC UNIT UNDER THE PERFORATED PLATE CONFIGURATION}

In order to evaluate ESP performance with the perforated plate, a series of experiments was conducted to measure fly ash particle concentrations in the AHPC unit. Two sampling locations were selected at the inlet of the AHPC and the location between the perforated plates and bags. The dust loading, measured by EPA Method 5, was 1.674 grains/scf at the inlet of the AHPC and reduced to 0.064 grains/scf in front of the bag when the current was $1.5 \mathrm{~mA}$. The resulting collection efficiency of the ESP alone was $96.2 \%$, significantly higher than the ESP collection efficiency of $95 \%$ achieved in the previous AHPC studies (3), even though the current was only $1.5 \mathrm{~mA}$. This indicates an improvement of electrostatic precipitation of the AHPC system with the perforated plates compared to the previous design. The results are also in agreement with the observed low $\mathrm{K}_{2} \mathrm{C}_{\mathrm{i}}$ values. Particlesize distributions were measured in front of the bag (between the perforated plate and bag) under different current levels by the aerodynamic particle sizer (APS) system. The number median diameter of the fly ash particle flowing toward the bag was $1.4 \mu \mathrm{m}$ and the mass median diameter was $6.6 \mu \mathrm{m}$ under several conditions. The respirable mass concentrations, plotted as a function of corona current, are shown in Figure 17. Obviously, the higher current resulted in a lower respirable mass concentration. The respirable mass concentration was $205.8 \mathrm{mg} / \mathrm{m}^{3}$ at a current of $0.37 \mathrm{~mA}$ and reduced to $93.8 \mathrm{mg} / \mathrm{m}^{3}$ at a current of $1.5 \mathrm{~mA}$, a $54.4 \%$ decrease. However, the respirable mass concentration was only reduced to $65.7 \mathrm{mg} / \mathrm{m}^{3}$ when the current was further increased to $3 \mathrm{~mA}$. This indicates that the ESP section in the AHPC can function very well even at a relatively low current level. The average respirable mass concentration in front of the bag (between the perforated plate and bag) when the power was off was approximately $660 \mathrm{mg} / \mathrm{m}^{3}$, which corresponds to a $85.8 \%$ and a $89.6 \%$ ESP collection efficiency of respirable mass at the currents of 1.5 and $3.0 \mathrm{~mA}$, respectively. Both are higher than the $83 \%$ ESP collection efficiency of respirable mass in the previous design (3). Again, the results demonstrate a better ESP performance of the perforated plate AHPC system compared to the previous design.

\section{CONCLUSIONS}

A series of experiments was carried out to evaluate the effect of several variables, including bag type, electrode type, perforated plate (hole size, opening area, alinement) and operating parameters (current level, pulse trigger pressure drop), on overall AHPC performance and bag protection. The experimental results demonstrated the following: 


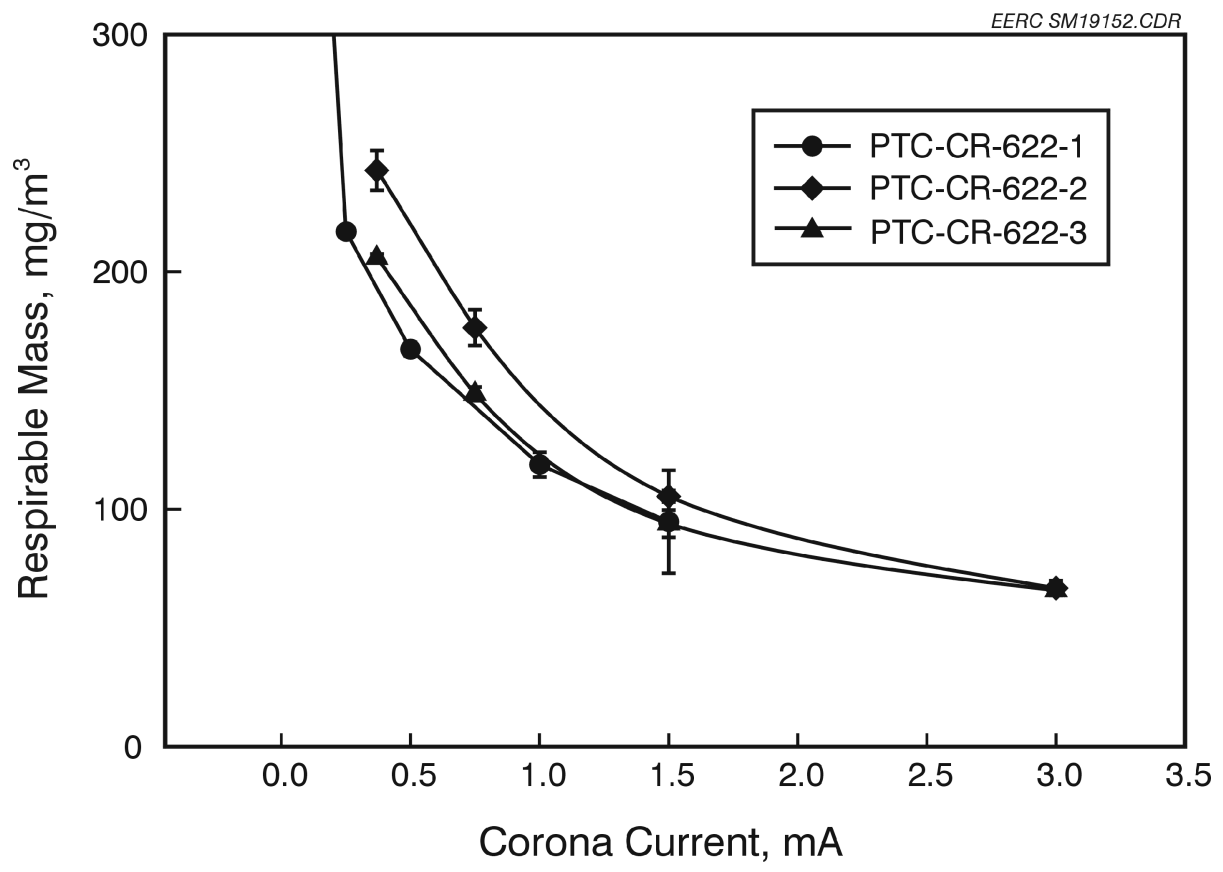

Figure 17. Effect of corona current on respirable mass in AHPC.

- The perforated plates with an open area around $50 \%$ and the hole sizes of 1.5 and 2.0 in. [0.038 and $0.051 \mathrm{~m}]$ were tested in hot coal combustion experiments. The current to bag was less than $2 \mu \mathrm{A}$ under the two perforated plate configurations (1.5 and $2.0 \mathrm{in}$. [0.038 and $0.051 \mathrm{~m}])$. The results are in agreement with the theoretical calculations in the previous study $(1,2)$ and indicate that this configuration provides adequate electrical protection of the bags.

- The spacing between the PTB was varied from 2.0 to 3.0 in. [0.051 to $0.076 \mathrm{~m}$ ]. The current to bag was kept at a low level under the two PTB spacings, indicating that both spacings provided adequate bag protection.

- Three different bags were used during the study. Results show the perforated plates can provide extremely good protection on the three different bags. No electrically induced damage was observed for all three bags based on the visual inspection at the end of the experiments.

- The perforated plate concept also benefits AHPC overall performance by serving as a collection plate to remove fly ash from the flue gas. The perforated plate AHPC system demonstrated long bag-cleaning interval and low average pressure drop across the system at a low current level $(1.5-3.0 \mathrm{~mA})$ and a high $\mathrm{A} / \mathrm{C}$ ratio of $12 \mathrm{ft} / \mathrm{min}(3.7 \mathrm{~m} / \mathrm{min})$. The residual drag was in the range from 0.25 to $0.35 \mathrm{in} . \mathrm{H}_{2} \mathrm{O} / \mathrm{ft} / \mathrm{min}$, showing an excellent bagcleaning ability under the perforated plate configuration. All the experimental data show that it is the best achieved to date. 
- The 2.0-in. $(0.051-\mathrm{m})$ hole perforated plate configuration demonstrated a better AHPC overall performance than the 1.5 -in. $(0.038-\mathrm{m})$ hole perforated plate configuration in terms of longer bag-cleaning interval (300 minutes for $2.0 \mathrm{in}$. [0.051 m] and 200 minutes for $1.5 \mathrm{in} .[0.038 \mathrm{~m}]$ at the end of the tests), lower $\mathrm{K}_{2} \mathrm{C}_{\mathrm{i}}$, and lower residual drag. However, the 1.5 -in. $(0.038-\mathrm{m})$ perforated plates may provide better bag protection.

- The perforated plate (1.5-in. [0.038-m] hole size) AHPC functioned very well at both of the two PTB spacings of 2.0 and 3.0 in. $(0.051$ and $0.076 \mathrm{~m})$ with a low $\mathrm{K}_{2} \mathrm{C}_{\mathrm{i}}$ of 1.8 . The residual drag was around $0.25 \mathrm{in} . \mathrm{H}_{2} \mathrm{O} / \mathrm{ft} / \mathrm{min}$ at the PTB of $2.0 \mathrm{in} .(0.051 \mathrm{~m})$ and increased to around 0.33 at the PTB of 3.0 in. $(0.076 \mathrm{~m})$, indicating a better bag- cleaning ability at shorter PTB spacing.

- Both the calculated $\mathrm{K}_{2} \mathrm{C}_{\mathrm{i}}$ and APS measured results indicated an improvement in ESP collection efficiency with the perforated plate AHPC system.

- The perforated plate AHPC system demonstrated its ruggedness and acceptable performance under the high dust-loading (22.8 grain/scf) and high-voltage power-off conditions.

\section{REFERENCES}

1. Miller, S.J.; Zhuang, Y.; Collings, M.E.; Olderbak, M.R.; Gebert, R.; Davis, D. Advanced Hybrid Particulate Collector; Quarterly Technical Progress Report, Phase III, for U.S. Department of Energy Contract No. DE-FC22-99FT40719; Energy \& Environmental Research Center: Grand Forks, ND, April-June 2000.

2. Miller, S.J.; Zhuang, Y.; Collings, M.E.; Olderbak, M.R.; Gebert, R.; Davis, D. Advanced Hybrid Particulate Collector; Quarterly Technical Progress Report, Phase III, for U.S. Department of Energy Contract No. DE-FC22-99FT40719; Energy \& Environmental Research Center: Grand Forks, ND, July-September 2000.

3. Miller, S.J.; Olderbak, M.R.; Zhuang, Y. Advanced Hybrid Particulate Collector; Final Technical Report, Phase I and II, for U.S. Department of Energy Contract No. DE-AC2295PC95258; Energy \& Environmental Research Center: Grand Forks, ND, Dec 2000. 